OPEN ACCESS

Edited by:

Giamila Fantuzzi,

University of Illinois at Chicago,

United States

Reviewed by:

Nandini Ghosh,

Vidyasagar University, India

Ramkumar Kunka Mohanram,

SRM University, India

${ }^{*}$ Correspondence:

Meirong $\mathrm{Li}$

meirong811225@126.com

Xiaobing Fu

fuxiaobing@vip.sina.com

Specialty section:

This article was submitted to Inflammation,

a section of the journal

Frontiers in Immunology

Received: 17 March 2021

Accepted: 27 May 2021

Published: 16 June 2021

Citation:

LiM, Hou Q, Zhong L, Zhao Y and Fu X (2021) Macrophage Related Chronic Inflammation in Non-Healing Wounds.

Front. Immunol. 12:681710.

doi: 10.3389/fimmu.2021.681710

\section{Macrophage Related Chronic Inflammation in Non-Healing Wounds}

\author{
Meirong $\mathrm{Li}^{1,2,3,4^{*}}$, Qian Hou ${ }^{1,2,3}$, Lingzhi Zhong ${ }^{1,2,3}$, Yali Zhao ${ }^{4}$ and Xiaobing Fu ${ }^{1,2,3 *}$ \\ ${ }_{1}^{1}$ Research Center for Tissue Repair and Regeneration Affiliated to the Medical Innovation Research Division and $4^{\text {th }}$ Medical \\ Center, PLA General Hospital and PLA Medical College, Beijing, China, 2 PLA Key Laboratory of Tissue Repair and \\ Regenerative Medicine and Beijing Key Research Laboratory of Skin Injury, Repair and Regeneration, PLA General Hospital, \\ Beijing, China, ${ }^{3}$ Research Unit of Trauma Care, Tissue Repair and Regeneration, Chinese Academy of Medical Sciences, \\ Beijing, China, ${ }^{4}$ Central Laboratory, Trauma Treatment Center, Central Laboratory, Chinese PLA General Hospital, Hainan \\ Hospital, Sanya, China
}

Persistent hyper-inflammation is a distinguishing pathophysiological characteristic of chronic wounds, and macrophage malfunction is considered as a major contributor thereof. In this review, we describe the origin and heterogeneity of macrophages during wound healing, and compare macrophage function in healing and non-healing wounds. We consider extrinsic and intrinsic factors driving wound macrophage dysregulation, and review systemic and topical therapeutic approaches for the restoration of macrophage response. Multidimensional analysis is highlighted through the integration of various highthroughput technologies, used to assess the diversity and activation states as well as cellular communication of macrophages in healing and non-healing wound. This research fills the gaps in current literature and provides the promising therapeutic interventions for chronic wounds.

Keywords: chronic inflammation, chronic wound, macrophage, heterogeneity, aging, diabetes, multidimensional analysis

\section{INTRODUCTION}

Skin wound repair is a critical process for the restoration of skin integrity. It is composed of three sequential and over-lapping wound healing phases: inflammation, proliferation and remodeling (1). An inflammatory phase involves clot formation, platelets released factors to attract neutrophils and macrophages infiltration into the wound and the phagocytic removal of bacteria and debris (2-4). Since then, the wound is cleaned and get ready for tissue regrowth. Precisely programmed initiation and resolution of inflammatory stage is necessary to pursue tissue repair $(5,6)$. In the proliferative phase, wound cells include keratinocytes, endothelial cells, and fibroblasts, cover and fill the defect through proliferation and migration, and participate in re-epithelization, revascularization and extracellular matrix (ECM) deposition, respectively. In the remodeling phase, the myofibroblasts undergo apoptosis and newly formed granulation tissues are reorganized, and then lead to tissue homeostasis (7-11). However, interruptions or defects in these delicate phases may lead to a nonhealing wound state $(6,12)$.

The prevalence of chronic wounds increases each year and is associated with a variety of conditions, such as old age, obesity, vascular disease, and diabetes (13). There were approximately $\sim 4.5,9.7$, and 10 million patients suffering from pressure, venous, and diabetic ulcer wound 
worldwide in recent years. The delay in wound repair has serious effects on patients' quality of life and poses a significant burden on patient's caretakers (14). Currently, well-established standard wound care for chronic wounds include pressure off-loading, removal of necrotic tissue, pathogenic suppression, and topical wound dressings $(15,16)$. And advanced strategies include growth factor-based therapy [platelet-derived growth factor (PDGF)], biological dressings (acellular extracellular matrices and cell-containing skin substitutes) are also available for wounds with poor response to standard care. Although the various treatments for chronic wound, there is still a significant number of patients suffer from lower limb amputation due to the further deterioration of the wounds (17). Even more unfortunately, the occurrence of chronic wounds is rises at a higher rate than the emergence of novel and effective treatment strategies.

Chronic wounds are defined as wounds stalled in a constant and excessive inflammatory state (10). Considerable evidence revealed that chronic wounds are closely associated with impaired phenotype transition of pro-inflammatory macrophages to anti-inflammatory phenotypes in wounds (10, 18-20). Macrophages play essential roles in the orchestration of transitions among three healing phases. Their phenotype readily changes according to spatiotemporal cues during repair (21). Many functional attributes ascribed to macrophages are found in skin wound models, such as scavenging, phagocytosis and antigen presentation in inflammatory phase (22), stem cell recruitment and revascularization in proliferative phase (23), and extracellular signaling transduction in remodeling phase, owing to their plasticity and heterogeneity (24). Recently, particular attention has been paid to their resolution of inflammation and shift toward regeneration (25). And macrophages were also recognized as "background actor" that participate in the immunomodulation in numerous diseases (26). This immune cell population was considered as a promising therapeutic target and can potentially be manipulated in a tissuespecific manner. For example, pro-inflammatory macrophage depletion have a universal protective effect on acute kidney injury (27). Monoclonal antibodies to inhibit macrophagic proinflammatory pathways achieve therapeutic efficacy in osteoarthritis (28). Therefore, a review of the plasticity, flexibility, and heterogeneity of macrophages under physiological and pathological conditions can not only provide clues to enable modification of improper kinetics in the macrophage response in chronic wounds, but also contribute to the understanding and identification of novel therapeutic targets for other injured tissues.

In this review, we first present the origin, function, and heterogeneity of wound macrophages. Subsequently, we discuss factors that contribute to the impaired activation and functions of macrophages in non-healing wounds. We highlight current biotherapy methods for restoring the function of macrophages. Finally, important molecular targets and novel macrophagebased treatment for chronic wounds are proposed from the perspective of single-cell sequencing.

\section{MACROPHAGE BIOLOGY IN WOUND HEALING}

Macrophages in wounds originate from two primary sourcestissue resident and bone marrow, the latter occupy a larger proportion and play dominant roles in wound repair (29-31). Their essential roles in wound healing have long been well-established in classical macrophage depletion model. A transgenic mouse model of inducible macrophage depletion revealed a prolonged inflammation, disturbed neovascularization, impaired fibroblast differentiation and delayed healing after non-selectively abrogate macrophages in wounds, which supported the notion that macrophages were key regulators to ensure proper healing $(32,33)$. And the selective depletion of macrophage at different stages of wound repair implied that macrophages took on distinct roles throughout the healing process (34).

\section{Roles of Macrophages in Inflammation Phase}

Resident and recruited macrophages play essential roles in the tissue injury response (35). After an injury, resident dermal macrophage are the earliest responders acting to induce the inflammatory response through the release of hydrogen peroxide, which leads to sequentially recruit blood neutrophils and monocytes. Subsequently, recruited monocytes further differentiate into macrophages under NADPH oxidase 1 and 2 (NOX1 and NOX2) $(30,31,36,37)$. During early wound healing, macrophage exhibits an inflammatory phenotype, known as the classically activated M1 macrophage. They act as the first line of defense against pathogen through mainly two ways, namely, recognizing pathogen-associated modifying proteins (PAMPs) on the surfaces of bacteria or fungi to form phagolysosome, and releasing antibacterial mediators, such as reactive oxygen species (ROS) and reactive nitrogen species $(38,39)$. Moreover, they are involved in removal of cellular debris and clearing apoptotic neutrophils (40). And they produce numerous pro-inflammatory cytokines and chemokines, such as the tumor necrosis factor- $\alpha$ (TNF- $\alpha$ ), interleukin-1 $\beta$ (IL-1 $\beta$ ), monocyte chemoattractant protein-1 (MCP-1), and chemokine (C-C motif) ligand 2 (Ccl2), to attract defense components and stimulate proliferation of wound cells, such as fibroblasts and keratinocytes. Furthermore, M1 macrophages seem to involve in the initiation of angiogenesis through secretion of angiogenic stimulators including vascular endothelial growth factor (VEGF), basic fibroblast growth factor (FGF2), IL-8, and CCL5 (41).

\section{Roles of Macrophages in Proliferation Phase}

In the following phase, the classically activated M1 phenotype gradually skews toward an alternatively activated M2 phenotype, which is a determining event for the transition from the inflammation phage to the proliferation phase $(42-45)$. The M2 phenotype is known as the healing-associated macrophage 
with downregulated inflammatory factors and upregulated antiinflammatory cytokines, including TGF- $\beta$, IL-10, and growth factors, such as platelet-derived growth factors (PDGF), resistinlike molecule- $\alpha(\operatorname{Relm} \alpha)$, epidermal growth factor, and vascular endothelial growth factor- $\alpha$ (Vegfo), that drive tissue repair (18, 20, 46, 47).

Because of the high plasticity of macrophage, M2 macrophage involved in healing are currently further categorized into three different subtypes (M2a, M2b,and M2c) (35, 46, 48, 49) (Figure 1). M2a macrophages become more prevalent as wound healing progresses, and produce high levels of arginase1 (Arg-1), PDGF, insulin-like growth factor-1 (IGF-1) and other cytokines (50). Moreover, as a pro-fibrotic phenotype, they directly secrete the fibrosis-related proteins contributing to collagen deposition in wounds (51-53). They also serve to promote angiogenesis, as well as proliferation, migration, and differentiation of fibroblasts (54). M2b macrophages are considered as the mixed regulatory phenotype which balance anti-inflammatory and pro-inflammatory functions, due to their production of pro-inflammatory cytokines (e.g., TNF- $\alpha$, IL-6, and IL-1) as well as large amounts of anti-inflammatory cytokine IL-10 along with low levels of IL-12 $(55,56)$. Moreover, M2b macrophages derived exosomes are abundant mRNAs encoding proinflammatory cytokines, chemokines, and regulation factors compared with M2a macrophages (57). Thus, M2b macrophages may represent an intermediate between $\mathrm{M} 1$ and $\mathrm{M} 2 \mathrm{a}$ polarization states (58). M2c macrophages are considered as tissue repair macrophages which exhibit strong antiinflammatory activities by releasing large amounts of IL-10 and augmenting the behavior of regulatory T-cells $(6,59,60)$. Furthermore, they play a role in angiogenesis through increased endothelial cell migration and tube formation $(41,61)$. Additionally, phagocytosis of wound debris, and the deposition of ECM components has also been demonstrated in M2c macrophages (54).

M2 macrophages also recruit stem cells to wounds, which are an important driving force in tissue repair, exerting tissue reparative effects through paracrine signaling $(62,63)$. Silva et al. showed that macrophage-derived GPNMB promotes the polarization of the M1 phenotype into the M2 phenotype (64). The later facilitates the mobilization of mesenchymal stem cells (MSCs) to the wound, thereby improving wound healing (65). However, the subpopulation of M2 macrophages that plays a role in the recruitment of MSCs has not been identified to date. Moreover, M2c macrophages have been shown to secrete MMP9 to attract vessel associated, blood-derived stem cells to fulfill the above-mentioned function of angiogenesis in injured sites (66).

\section{Roles of Macrophages in Remodeling Phase and Regeneration}

Prolonged activation of M2 macrophages can lead to excessive wound healing and ultimately fibrosis (67). Therefore, the number of macrophages starts to decline during the remodeling phage. The remaining macrophage play a role in tissue remodeling (68). Matrix metalloproteinase are major proteolytic enzymes involved in the turnover of the extracellular matrix (ECM) during cutaneous wound repair. MMP-10 is derived from macrophage shaped ECM deposition indirectly by upregulation of MMP-8 and MMP-13 (52). Furthermore, the mannose receptor-mediated endocytic

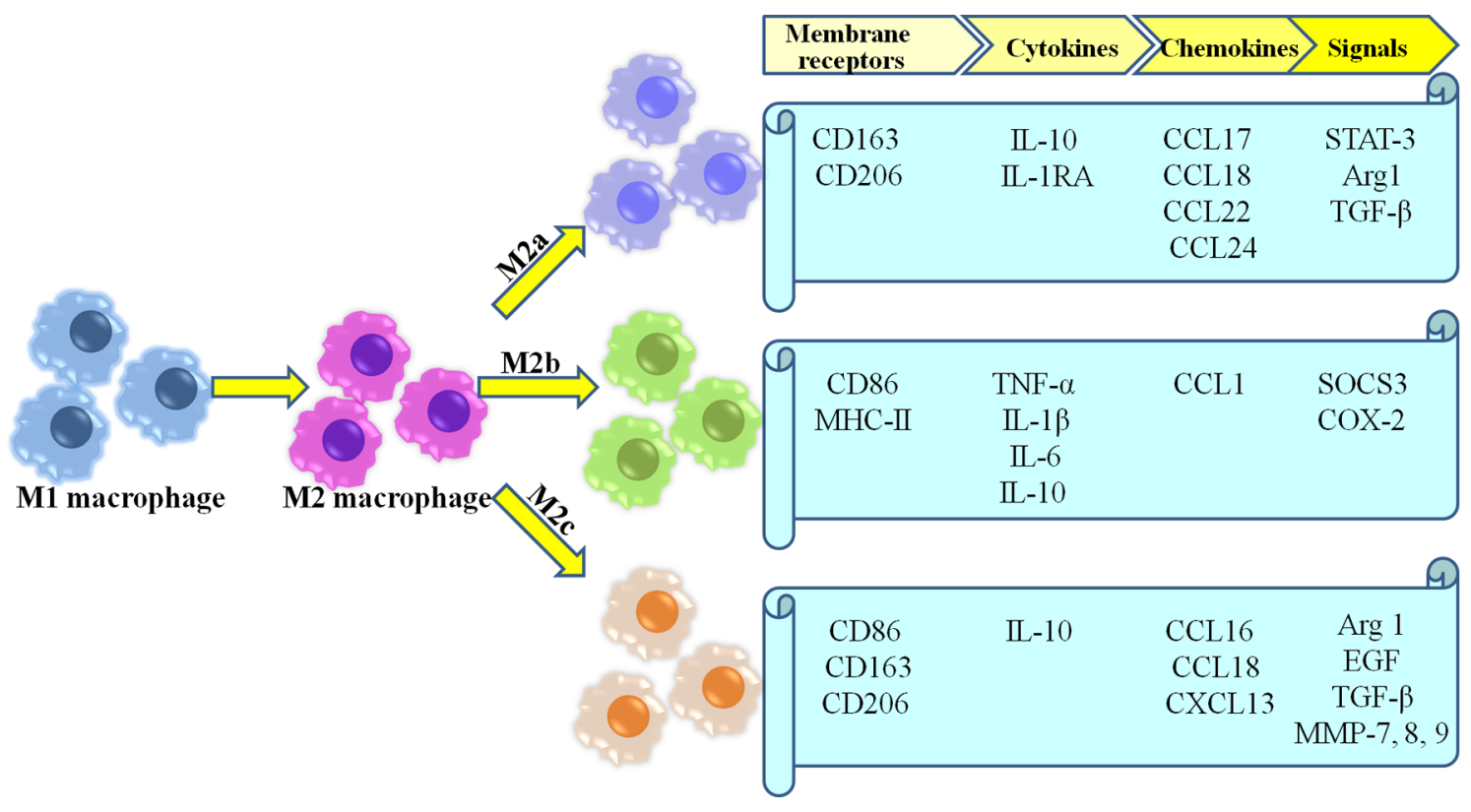

FIGURE 1 | Most common characteristics of M2 macrophages subgroups. 
pathway for degradation collagen was revealed as another dominant path for collagen turnover by M2 macrophages (69).

Previous research links macrophages to hair follicle growth, as perifollicular resident macrophages prompt the entry of hair follicle (HF) stem cells into the anagen phase of growth through Wnt-related apoptosis signaling (70, 71). Full-thickness skin wounds usually leaves hairless scars, and macrophages are important for regeneration. The study of Martinot et al. showed that hair-bearing areas heal faster than areas lacking HFs (72). Recent studies showed that M2 macrophages release growth factors, such as the hepatocyte growth factor (HGF) and insulin-like growth factor 1 (IGF-1) to activate stem cells and facilitate HF regeneration in a skin mechanical stretch model (73). Results by Wang et al. revealed that M2 macrophages activate HF stem cells in the later stage of wound healing, leading to a telogen-anagen transition around the wound and de novo $\mathrm{HF}$ regeneration in wound-induced hair follicle neogenesis (WIHN) (74). Osaka et al. found that the apoptosis signal-regulating kinase 1 (ASK1) is needed for the regulation of infiltration and activation of macrophages, and required for macrophage-dependent hair regrowth in wounding-induced hair regrowth (75). However, the phenotypes of macrophage subgroups associated with $\mathrm{HF}$ regeneration must be further confirmed, and the emergence timing and the quantity of this specific subgroup may directly determine whether the HF can regenerate. Furthermore, there is lacking evidence on whether the regeneration of other appendages in the injured sites, such as sweat glands and sebaceous glands, are closely associate with local macrophages.

In summary, macrophages in wounds act as the "Monkey King" in Chinese myths. They change according to their surrounding environment and needs, and perform their due functions. Therefore, selective targeting of macrophage subpopulations for pro-healing therapy may provide an attractive strategy in regenerative processes. However, the understanding of spatiotemporal cues of each subpopulation of macrophages during the repair process is still limited. We must further explore the plasticity of macrophages and discover more functional subgroups to enable better regulation of the repair process to promote wound repair and regeneration.

\section{SYSTEMIC AND LOCAL FACTORS OF MACROPHAGE DYSFUNCTION IN NON-HEALING WOUNDS}

As wounds heal, the tight regulation of the macrophage phenotype switching from a M1-proinflammatory to a M2anti-inflammatory (pro-healing) phenotype contribute to the smooth progress of the repair process (76-78). However, under pathological condition, such as ageing, obesity, infection, and diabetes, M1 macrophages in wounds were restrained with an incomplete switch to M2 phenotype, resulting in the stall of the repair process at inflammatory phase $(10,79,80)$ (Figure 2$)$. The mechanisms behind the persistent inflammatory macrophage phenotype in chronic wounds have been gradually identified.

\section{Systemic Factors of Macrophage Dysfunction}

Multiple studies reported that macrophages are prone to dysregulation under pathophysiological conditions such as

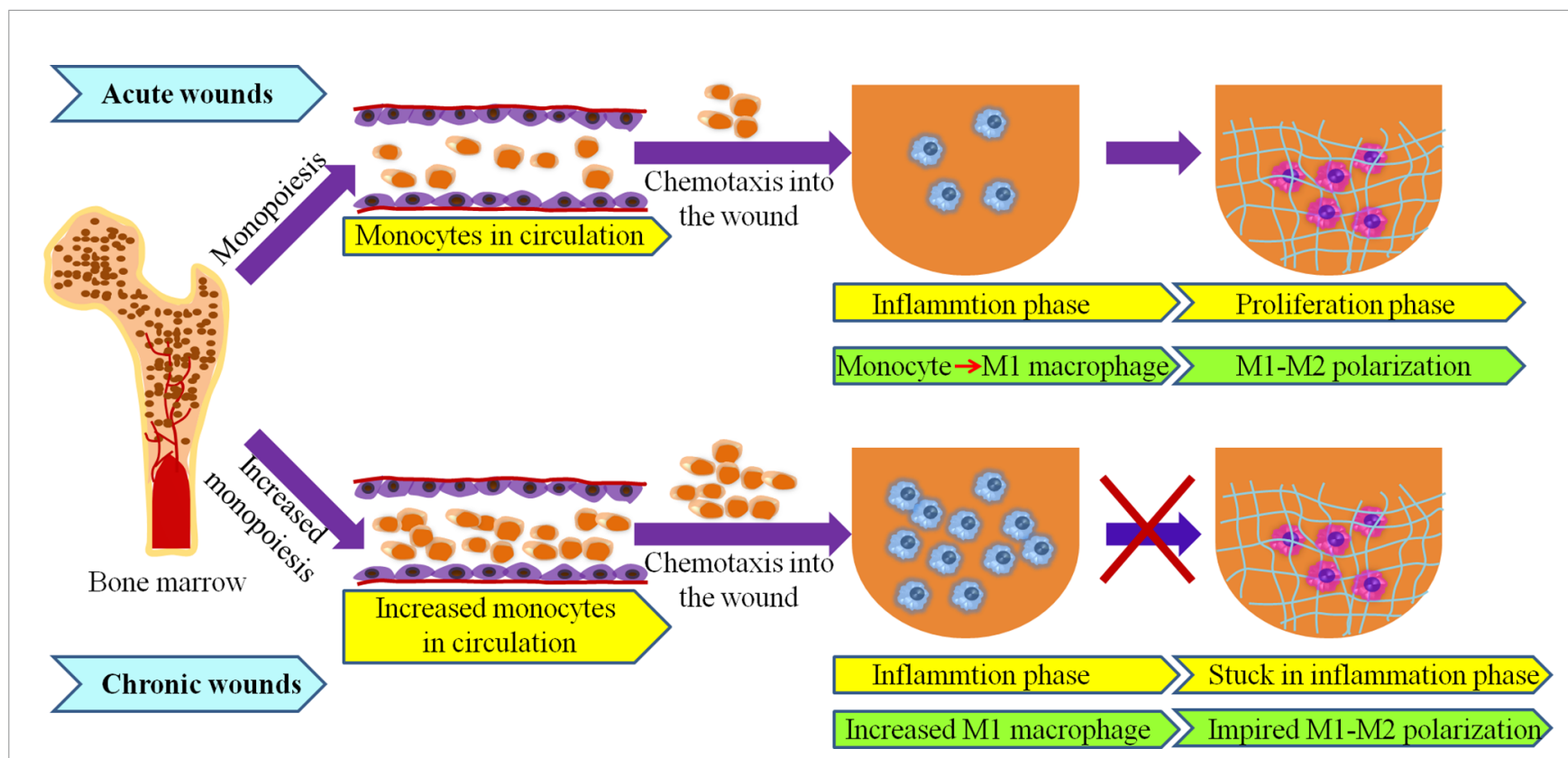

FIGURE 2 | Macrophages originate from bone marrow in acute and chronic wounds. High numbers of bone marrow-produced monocytes under elderly, obese and diabetes may lead to increased number of macrophage in chronic wound. Transition from M1- to M2- phenotypes is impaired in chronic wounds. 
ageing, obesity, and diabetes, and their aberrant activities are present not only at the wound site, but also in bone marrow (BM) and blood circulation (2, 81-83). Alteration in the number and function of macrophage have been revealed in chronic wounds, which are closely related to hematopoietic disruption and particularly to myeloid skewing $(67,84-86)$. This is known as increased monopoiesis (Figure 2).

In aging mice, the hematopoietic stem and progenitor cells (HSPCs) showed restricted diversity and a preferential myeloidbiased differentiation, which was reflected by enhanced accumulation of the myeloid progenitor in aged mice (87). The comparative analysis of expression profiles of HSPCs suggested that the myeloid differentiation related genes in aged mice, such as Runx1, Hoxb6, and Osmr are upregulated while lymphopoiesis genes are downregulated compared with those of young mice (88). Dramatic changes in the HSPCs milieu or niche in aging mice were attributed to the aging process and myeloid differentiation bias. Niche factors, such as proinflammatory cytokine RANTES, secreted from aging stromal cells and differentiated blood cells have been considered as a major factor in this HSPCs subtype shift $(89,90)$. Ergen et al.'s study showed that RANTES knockout mice rescued aging-associated myeloid-biased lineage differentiation (89).

Obesity and aging share many common traits in term of immunity and metabolism $(91,92)$. Several studies showed that obesity modifies the composition of adipose tissue in BM and restrains the generation of osteoblastic cells from mesenchymal progenitors, thereby affecting BM homeostasis. Moreover, adipocytes in BM are key limiting factors of the hematopoietic function in obesity through direct and indirect means $(84,93)$. Obesity induced oxidative stress is a key driver for the aberrant HSPCs activity skewed toward the granulocyte-macrophage progenitors via dysregulation of the expression of Gfil in HSPCs $(84,86)$. Additional studies indicate that an epigeneticbased mechanism is involved in the programming of macrophages biased toward a proinflammatory phenotype under obesity. HSPCs display increased levels of Jmjd3, a member of the JumanjiC (JmjC) family of histone demethylases, which responds to the decreased $\mathrm{H} 3 \mathrm{~K} 27 \mathrm{me} 3$ at the promoter region of proinflammatory IL-12 (94). This epigenetic feature is passed down to the macrophages at the wound sites, making them predisposed toward a proinflammatory phenotype (94).

Preprogrammed HSPCs committed towards the myeloid lineage and increased proportions of BM myeloid progenitors have also been found in diabetic mice during homeostasis and following injury, which results in an enhanced myeloid output (95-97). An elevated number of circulating monocytes was also revealed in diabetic patients (2). Furthermore, the higher potential to form granulocyte/macrophage colony forming units in BM isolated cells, and the increased number and proliferation of granulocyte-macrophage progenitors and common myeloid progenitors have also been found in diabetes (98). These results suggest a mechanistic link between neutrophils and monocytes. Research conducted by
Nagareddy et al. showed that the depletion of neutrophils normalized the monocyte level in diabetic mice. Mechanistically, neutrophils produced more S100A8/A9 which interacted with glucose- inducible receptor for advanced glycation end products (RAGE) on myeloid progenitor cells resulting in the enhanced release of monocytes under hyperglycemia. Moreover, S100A8/A9-initiated monocytosis was dampened when blood glucose drops back to normal (98). Furthermore, hyperglycemia induced higher expression of tyrosine hydroxylase and produced more catecholamines in the spleen leukocyte of diabetic patients and mice, via an interaction with the $\beta 2$ adrenergic receptor on the granulocyte macrophage progenitors, leading to enhanced monocytosis (99). However, the opposite trend was observed in the study by Yan et al. This suggests that T2DM causes reduced differentiation of HSPCs towards monocytes/macrophages through Dnmt1-dependent repressive modifications of myeloid lineage associated genes such as Notch1, PU.1 and Klf4 (100).

The above findings demonstrate that the wound M1dominant macrophage phenotype is set at the BM level. The microenvironment in the BM changes significantly under pathological conditions, such as aging, obesity, and diabetes, which predetermines the gene expression of HSPCs and dysregulates their differentiation potential and function. These aberrant signatures are preserved and passed down to monocytes, which further disrupt the polarization of macrophages and imbalance the M1/M2 phenotype throughout the course of wound healing. Therefore, these findings reveal a novel therapeutic approach for chronic wounds. Therapies target systemic changes in the BM niche and regulate monopoiesis of hemopoietic stem cells (HSCs) to influence peripheral phenotypes and restore the balance of $\mathrm{M} 1$ / M2 macrophages, which may improve the state of nonhealing wounds.

\section{Local Factors of Macrophage Dysfunction}

Presently, there are two theories regarding changes in the number of macrophages in chronic wounds. One is that a large number of macrophages infiltrate in chronic wounds as the results of increased monopoiesis, accompanied by an increase mobilization to the bloodstream. The other is that the number of macrophages is significantly reduced during the inflammatory phase in diabetic mice, which is attributed in part to a weakened chemotaxis into the wound $(65,101)$. The inconsistency in wound macrophage numbers between studies could result from technical differences in the evaluation of wound macrophage and requires further research. Nevertheless, in either case, chronic wounds are often described as being "stalled" in the inflammatory phase with an impeded M1/M2 phenotype transition at the later stages of wound healing. Several reports showed that this was not only related to the functional modifications in HSCs that are passed down to macrophage progeny, but that it was also associated with local effects mediated by the wound microenvironment $(2,43,102)$. 
The wound microenvironment has a predominant role on the behavior and functionality of healing cells. Macrophages are highly plastic and can change their phenotype and functions in accordance with local microenvironmental signals (103). According to the non-healing wound research, a large number of studies focused on diabetes-related chronic wounds. Both mouse and human diabetic wound conditioned media prefer to induce a proinflammatory macrophage phenotype of BM- derived macrophage in vitro, which suggests an imbalanced microenvironment $(43,44)$. The main cause of macrophage dysfunction with an increased M1/M2 macrophage ratio is composed of two main factors: (1) dysfunction of macrophages under pathological conditions; (2) numerous microenvironmental biomolecules.

\section{Dysfunction of Macrophages Under Pathological Conditions}

Cell senescence is a normal physiological process in the repair process. It promotes healing via releasing PDGF-AA (104). Conversely, it prevents fibrosis by driving the senescence of myofibroblasts (105). The rapid and effective clearance of these cells is essential for optimal repair outcomes (106, 107). In contrast, an excessive amount of senescent cells in the wound or a disturbance of senescent cell clearance may lead to impaired wound healing.

Similar to those found in wounds of elderly, a large amount of senescent cells accumulate in skin wounds of diabetic mice, and macrophages account for a large proportion of these cells (108). Wilkinson et al. found that macrophages derived from wounds of diabetic animals showed reduced polarization potential and prolonged inflammation, and generally presented a senescent phenotype with secretion of a senescence-associated secretory profile (SASP) (108). SASP is an important approach for a small number of senescent cells in tissues to exert significant local biological effects, and it is implicated in the occurrence of numerous chronic diseases (109-111). For example, proinflammatory SASP is thought to be involved in the development of insulin resistance and type II diabetes mellitus in both mice and humans (112, 113). Wilkinson et al., found that macrophages derived from diabetic murine exhibited senescence phenotype and reduced M2-polarization. And the SASP secreted by macrophages derived from wounds of diabetic mice was enriched in CXCR2 ligands, which induced fibrotic markers of fibroblasts and had the potential to promote the senescence in fibroblasts (108). Furthermore, wounds in diabetic mice treated with the CXCR2 antagonist showed reduction in macrophage senescence and local inflammation and facilitated wound closure, suggesting a novel avenue of targeting the CXCR2 receptor for potential therapeutic developments (108).

Therefore, the senescence of macrophages not only impairs their polarization from a proinflammatory phenotype to one that supports reparative processes, but also affects the wound microenvironment and biological functions of other repair cells through paracrine effects. There is also consensus in the literature that M1 macrophages in diabetic wounds suffer from dysfunctional efferocytosis due to reduced PPAR- $\gamma$ expression, resulting in increased accumulation of apoptotic cells at the wound site $(25,102,114)$. This burden, in turn, augments pro-inflammatory activity and sustains the inflammatory phase (25).

\section{Numerous Microenvironmental Biomolecules for Impaired M1 to M2 Polarization}

The wound microenvironment is highly complicated, and various factors have been shown to play negative roles in M1/ M2 phenotype transition, including metabolic-related outcomes, such as hyperglycemia, advanced glycation end products (AGE), oxidative stress products, and soluble molecules, such as inflammatory factors, neuropeptides, and wound microbes.

The hyperglycemic microenvironment affects the polarization of macrophages in both direct and indirect ways. Huang et al. showed that human monocyte cells (THP-1) were cultivated for 14 days under high or normal glucose conditions. The M1 type marker, CCR7, was significantly upregulated in THP-1 under the high glucose condition as compared to the normal glucose condition, which suggested a biased M1 macrophage (115). Indirectly, hyperglycemia induced generation of reactive oxygen species (ROS) and elevated methylglyoxal (MGO) levels. M2 macrophages are characterized as reductive macrophages, suggesting the redox regulation in macrophages physiology (116). M2 phenotype activation stimulates increased arginase- 1 activity and is accompanied by reduced ROS and NO generation. Sustained high levels of oxidative stress obstruct the M1/M2 polarization (117). The mutation of Nox2 or silenced p47 has been shown to inhibit NADPH oxidase to reduce the production of extracellular ROS, favoring the macrophage poise towards the M2 phenotype (117). An elevated MGO usually results in glycation and the increase of AGEs (118). Macrophages express M1 phenotype markers and secrete proinflammatory cytokines after treatment with AGE through activation of the MAPK pathway. Furthermore, AGE was found to induce M1 polarization via regulation of PDK4 (119).

As mentioned above, high glucose, AGE, or oxidative stress are known to inhibit the M1/M2 polarization and promote the expression of proinflammatory cytokines in over-activated M1 macrophages. Diabetic subjects have higher serum levels of TNFa, MCP-1 that is associated with failure to heal in diabetic foot wounds (120). Further, these proinflammatory can form a positive feedback loop to sustain a persistent proinflammatory wound macrophage phenotype. For example, Mirza et al. found that interleukin-1 $\beta$ (IL-1 $\beta$ ) and TNF- $\alpha$ as proinflammatory factors are increased in diabetic wound macrophages in both mice and humans (43). BM-derived macrophage exhibited a proinflammatory wound macrophage phenotype when cultured with conditioned medium of chronic wounds, supporting the notion that proinflammatory mediators are involved in the persistent inflammatory phenotype of macrophages in wounds (43). Therefore, a high proinflammatory environment is observed in chronic wounds, and inflammatory factors have 
the potential to impede M1/M2 polarization of macrophages which, in turn, contribute to sustaining the proinflammatory environment.

The increased accumulation of proinflammatory activity in wounds is derived from adipocytes due to their hypertrophy under diabetic condition $(18,121)$. Recently, numerous discoveries supported the concept that diabetes and metabolic syndrome are systemic inflammatory diseases (121). This strong association with adipocyte hypertrophy leads to lipotoxicity and excessive production of chemokine and cytokines (122). Moreover, the overexpansion of adipocyte triggers a stress state and eventually results in apoptosis to release inflammatory mediators and attract macrophages to the adipose tissue (123). This causes further infiltration of inflammatory cells, intensifying the secretion of inflammatory mediators, creating a systemic low-grade inflammatory state that may participate in high inflammation states of chronic wounds (124). Consequently, anti-inflammatory treatments may not only improve senescence and insulin resistance but also play an active role in accelerating wound repair.

Neuroregulatory factors are likewise altered in the wounds of diabetics. The expression of neuropeptides was reduced in the skin of diabetic rabbits, and it was accompanied by a chronic proinflammatory state, as indicated by a high M1/M2 macrophage ratio and an elevated proinflammatory cytokine expression, as well as impaired wound healing (125-127). However, the definite molecular mechanism remains unclear.

Chronic wounds are frequently accompanied by the invasion and infection of bacteria due to their unique microenvironment. Multiple species of bacteria have been isolated from chronic wounds, and several also affect the M1 to M2 polarization of macrophages (128). For example, Pseudomonas aeruginosa ( $P$. aeruginosa) is a frequently detected gram-negative pathogen in diabetic non-biofilm wounds $(129,130)$. It prolongs the presence of M1 macrophages in chronic wounds in two ways. P. aeruginosa produces LPS and binds to the TLR4 receptor complex in macrophages to promote the secretion of inflammatory cytokines (131). Moreover, the type III Secretion System (T3SS) virulence structure is a common trait among all $P$. aeruginosa clinical isolates, which functions as a conduit to directly translocate effector toxins into the target cells and result in inflammation (132). Therefore, $P$. aeruginosa affected wound healing may involve increasing the number of M1 macrophages in wounds accompanied by elevated proinflammatory cytokine production.

In summary, the unique and complex wound microenvironment of chronic wounds inhibits the polarization of macrophages from the inflammatory to the repair phenotype. Therefore, the inflammation phase of healing cannot transition to the proliferative phase in chronic wounds, and the proliferation of connective, endothelial, and epithelial tissue cannot be further completed (52). Consequently, targeted changes in the unbalanced microenvironment of chronic wounds may be of great significance to promote healing. Simultaneously, the imbalanced microenvironment changes have multiple-aspects and levels, determining that the multi-target treatment may be more effective than the single-target treatment in local wound treatment.

\section{BIOLOGICAL TREATMENT FOR RESTORATION OF MACROPHAGE FUNCTION}

Sustained increases in the number of wound macrophages and the dysregulation of their phenotypes, caused both by intrinsic alterations in HSPCs and by a local sophisticated microenvironment, lead to impaired wound healing. Recently, several therapeutic approaches aimed at restoration of macrophage function have garnered significant attention. Methods include systemic treatment via oral administration of drugs and local treatment through neutralizing antibodies, MSCs, and biomaterials are discussed.

\section{Systemic Treatment Strategies}

As mentioned in the previous section, the majority of macrophages in wounds are derived mainly from HSPCs. These already predisposed progenitor cells are partially responsible for the dysregulated macrophage polarization and prolonged inflammation in chronic wounds, which suggests that a HSPCs based therapy may improve the function of macrophages from the source.

Docosahexaenoic acid (DHA) is an omega-3 fatty acid, which is prerequisite for cell growth, development, and metabolic functions in mammals. It is also the precursor of several molecules that regulate the resolution of inflammation. The impairment of DHA synthesis affects macrophage plasticity and polarization both in vitro and in vivo through an Elovl2 (Elovl2-/-) deficient mice model, suggesting a potential role of DHA in regulating the function of macrophage progenitor cells (133). Further, Jia et al. have demonstrated that the accumulation of total macrophages (CD68+) in the wounds of diabetic rats treated with oral DHA remained unchanged, but there is a higher ratio of M2/M1 phenotype compared with diabetic rats, thereby promoting resolution of inflammation in diabetic wounds and accelerating wound healing. Moreover, in vitro differentiation experiments confirmed that secretory features of M1 and M2 macrophages differentiated from bone marrow-derived macrophages in the oral DHA group were similar to those in normal rats, but different from those of $\mathrm{M} 1$ and $\mathrm{M} 2$ macrophages in the diabetic group with more iNOS, TNF- $\alpha$, IL- $1 \beta$, and interleukin-6 in M1 macrophages and less Arg-1, interleukin10 , and TGF- $\beta 1$ in M2 macrophages. The same study implies that oral DHA in diabetic patients is able to correct the impaired plasticity of HSPCs, thereby improving resolution of inflammation, stimulating the transition into the proliferation stage, and thus promoting wound repair (134).

Chronic low-grade systemic inflammation is a common pathophysiological property of aging, obesity and diabetes (82, $135,136)$. It is associated with a higher content of proinflammatory macrophages (137-139). Prolonged and persistent systemic inflammation can be destructive to various tissues and impair wound healing (140). Consequently, antiinflammatory strategies focus on the inflammation resolution to stop or dampen the inflammatory response, which may ameliorate the systemic and local inflammation state. 
Apart from treatment of the primary disease, such as diabetes, improving complications caused by it, such as chronic wounds, requires further study.

\section{Local Treatment for Improvement of Unbalanced Microenvironment Pro-Inflammatory Microenvironment-Directed Approach}

Over-activated M1 macrophages contribute to the hyperinflammation state of chronic wounds by secreting high levels of pro-inflammatory factors. Neutralizing antibodies aim against these factors that silence M1 macrophages are a promising strategy for enhancing wound healing. Goren et al. found that on the seventh day of post-wounding in diabetic wounds, at the end of the inflammatory period, the administration of antiTNF-a or anti-F4/80 antibodies promotes re-epithelialization and closure of the wound, whereas the wound in the nontreatment group remains unhealed with scabs. Decreased levels of TNF-a, IL-1 $\beta$, and CCL2 (MCP-1) proteins were also found in wounds with anti-TNF-a or anti-F4/80. Overall, anti-TNF-a and anti-F4/80 therapies reduced the impact of M1 macrophages, and accelerated the healing of diabetic wounds (141). Furthermore, sustained expression of IL- $1 \beta$ in both of diabetic wounds mice and humans impaired the activity of PPAR- $\gamma$, which was closely associated with the switch in macrophage phenotypes. Therefore, blocking the proinflammatory cytokine IL-1 $\beta$ at the local sites or topical administration of PPAR- $\gamma$ agonists promoted a pro-healing macrophage phenotype and accelerated wound healing (43, 102, 142). Further, Arginase, as a specific phenotypic marker of M2 macrophages, is also widely expressed in other wound cells including keratinocytes, fibroblasts, and endothelial cells. It has been found to play critical roles in inflammatory response and cellular functions through controlling the local arginine concentration and regulating nitric oxide production $(143,144)$. Decreased arginase level has been found in tissue of chronic nonhealing (145). And local inhibition of arginase activity by genetic and pharmacological means significantly impedes wound repair with enhanced inflammatory infiltrate and delayed reepithelialization (146). Contrastly, Kavalukas et al. demonstrated that depression of arginase through a specific inhibitor 2(S)-amino6-boronohexanoic acid NH4 (ABH) significantly accelerated wound closure accompanied by increased granulation tissue formation and enhanced re-epithelialization (147). The inconsistency of these results may be related to the model used in the research, the means and degree of inhibiting arginase activity. Therefore, treatment strategies based on arginase needs further research.

Peace or inhibition of overactivated signaling pathways is another alternative approach. The AGE-RAGE signaling pathway is significantly enhanced in diabetic wounds, inhibiting macrophage polarization and M2 phenotypic macrophage function (148). Anti-RAGE antibody-applied wounds increased the number of neutrophils phagocytized by macrophages and promoted the phenotypic switch of macrophages from proinflammatory to pro-healing activities (148).

Oxygen radical scavengers have been reported to provide positive effects in the treatment of chronic wounds (149). For example, topically applied mepenzolate bromide to the wound bed considerably corrected the excessive and prolonged ROS production, and further decreased the level of pro-inflammatory cytokines and increased the level of pro-healing cytokines, results in a promotion of macrophage M2 phenotype polarization, thus accelerating the wound closure rate (150). Antioxidants $\alpha$-tocopherol and $\mathrm{N}$-acetylcystein showed a strong oxidative stress clearance through inhibition of the activity of two antioxidant enzymes, GPx and catalase. Chronicity was reversed in non-healing wounds by treatment with these antioxidants (151). Moreover, natural or synthetic antioxidant compounds, such as sulforaphane (SFN), wogonin (WG), oltipraz (OTZ), and dimethyl fumarate (DMF) are used to evaluate their effect on macrophage polarization. They could elicit phenotypic changes from the M1 gene signature to M2 gene signature via indication of the nuclear factor erythroid 2-related factor 2 (Nrf2), a key member of antioxidant regulators (152).

The treatment strategies presented in this review are therefore presented principally to weaken and combat the adverse factors in chronic wounds, balance the inflammatory wound microenvironment, promote the polarization of macrophages, and finally facilitate the wound repair process into the proliferative stage.

\section{Macrophage-Directed Gene Therapy Approach}

CD163 has been proposed as a specific marker for macrophages with an anti-inflammatory phenotype. It has been shown that using a modified nanoparticle, polyethylenimine (PEI) grafted with a mannose receptor ligand (Man-PEI) to induce CD163 in human primary macrophages lead to changes in the secretion profile and induced anti-inflammatory responses (153). Further, Ferreira et al. likewise used this cell-directed nanotechnology to induce expression of the CD163 gene in THP-1 and human primary macrophages. They found that polarized M2 macrophages have the ability to promote a faster wound healing by interacting with keratinocytes and fibroblasts (154). This precise targeting method can avoids limitations and side effects due to the heterogeneity of chemical-based therapy on different cells and may become an important strategy to reverse chronic wounds.

\section{Exogenous Cell Supplement Approach}

Chronic wounds are characterized by the polarization barrier of macrophages leading to a higher proportion of M1 phenotypic macrophages and a lower proportion of M2 phenotypic macrophages. A direct addition of exogenous M2 macrophages to the wound may promote wound repair. For example, after activation by hypoosmotic shock, peripheral blood-derived macrophages exhibited anti-inflammatory features and subsequently secreted a large number of repair-related signature genes, such as TGF- $\beta$, FGF-8, TNF receptors, VEGF, 
and GM-CSF (155). These activated macrophages with antiinflammatory properties may be beneficial for wound repair. Presently, this method lacks sufficient supporting data, and further research is required.

Mesenchymal stem cells (MSCs) are high multi-potentiality residing in different tissues including $\mathrm{BM}$, adipose tissue, the umbilical cord, and skin $(156,157)$. In addition to their selfrenewal and differentiation capacity into several lineages, their secreted products' impact on a variety of resident and recruited cells are essential for tissue homeostasis and wound repair, and have therefore been explored as cell therapies $(10,156)$. Their application in acute and chronic wound models has been successful, resulting in resolution of wound inflammation, and enhancement of angiogenesis and acceleration of wound closure (158-161).

Evidence indicates that MSCs exert powerful modulating effects on the immune system, in particular with regard to the immunoregulatory function on macrophages (162). One of the mechanisms of MSC action on macrophages is via their recruitment. For example, BM-MSCs conditioned medium significantly accelerates migration of macrophages in vitro (163). Subcutaneous injection and topical application of BMMSCs conditioned media in wounds increased proportions of macrophages and endothelial progenitor cells compared with control group, thus enhancing wound healing (163). Macrophage recruitment by MSCs may be attributed to high levels of secreted chemoattractants CCL3 (MIP-1a), MIP-2, and CCL12 (MCP-5) (10). Another mechanism of MSC action on macrophages is by augmentation macrophages to engulf apoptotic neutrophils, which is attributed to upregulation of the intercellular adhesion molecule-1 (ICAM-1) on macrophages or enhanced release of soluble extracellular superoxide dismutase (SOD3) from MSCs (164-166). Another mechanism of MSC action on macrophage is via enhancement of M1-M2 polarization and increasing the frequency of M2 macrophages in wounds. Several in vitro studies showed that macrophage facilitated differentiation into M2 phenotypes when co-cultured with MSCs or MSCs derived secretomes (167-170). MSCeducated macrophages exhibited secretory characteristics of M2 phenotype with increased expression of IL-6 and IL-10 and decreased expression of TNF- $\alpha$ and IL-12 (171). Furthermore, MSCs were found to regulate the macrophage phenotype in vivo (169). MSCs or MSCs conditioned medium treatment of wounds produced high levels of IL-10 and VEGF but low levels of TNF- $\alpha$ and IL- 6 and induced an accumulation of M2 macrophages in diabetic mice $(171,172)$. A panel of MSC secreted mediators were studied for their immunomodulatory mechanisms. For example, prostaglandin E-2 (PGE-2), a secreted mediators from MSCs, had a direct effect on the macrophages M1-M2 polarization $(169,173)$. This process is mainly regulated by PGE2 binding to the EP4 receptor on M1 macrophages, and it involves two pathways including CREB and PI3K signaling (169). Furthermore, MSCs released of the tumor necrosis factor- $\alpha$ (TNF- $\alpha$ )-stimulated protein 6 (TSG-6) increased when they were co-cultured with activated macrophages. Topical delivery of MSCs also resulted in TSG-6 release at wound sites, and suppressed TNF- $\alpha$ to play an immunosuppressive role in vivo (174). Other possible mechanisms must be further developed and validated.

Currently, MSCs resolve the unrestrained and prolonged inflammation of chronic wounds in terms of numerous aspects, and are ideally suited for the treatment of chronic wounds (156). Further, MSCs have a unique property, namely, the capacity to sense the microenvironment in which they are located, which determines that its immunoregulatory function of MSCs reveals high plasticity $(156,175)$. Compared with the chemical-based or growth factor-based strategies, this marks an excellent property and allows for refinement of MSC-based cell therapies in the future $(176,177)$.

\section{Immunomodulatory Biomaterials-Based Approach}

Biomaterials can provide suitable environments that enhance inherent biological activities and functions in repairing cells through appropriate biochemical cues (e.g., composition and surface chemistry) and biophysical cues (e.g., stiffness and surface topography) (178-180). An increasing amount of evidence shows that they can also influence the flexible nature of macrophages in wounds.

Immunomodulatory biomaterials, particularly the natural biomaterials, have shown regulation of the macrophage fate $(181,182)$. The decellularized dermal scaffold (DDS) is a skin tissue that removes cellular components and retains the ECM structure, which was shown to play a therapeutic role in wound repair (183). DDS in particular can regulate the transition of macrophages from the M1 pro-inflammatory phenotype to the M2 pro-repairing phenotype, thus promoting macrophage polarization $(184,185)$. He et al. suggested that amino acids produced by collagen degradation in DDS activated the acidsensing pathway in macrophages and induced fate transition (184). Further, the inherent components of the ECM, such as hyaluronic acid (HA), or the analogues of the ECM including chitosan, influence the M1-to-M2 phenotype switching (185, 186). Physical and chemical properties of biomaterials have a profound impact on the cellular behavior. For example, a high molecular weight of HA caused macrophages to take on antiinflammatory features, whereas a low molecular weight of HA resulted in the activation of M1 macrophages (187-189). Biomaterials composed of collagen and highly sulfated HA derivatives promoted switching from the M1 to M2 phenotype of macrophages. Keratin biomaterials have also been used in wound repair studies, and their ability to tune inflammation has been confirmed (190-192). In vitro studies have shown that primary macrophages inoculated into high molecular weight extracted keratin and keratin peptide coatings facilitated differentiation into M2c macrophages with anti-inflammatory behavior (190). Chitosan is similar to glycosaminoglycan in ECM, and filmed chitosan can promote higher macrophage production of IL-10 and TGF- $\beta 1$ anti-inflammatory cytokines as an indication of the M2 phenotype (193). Therefore, immunomodulatory biomaterials with the goal of promoting macrophage polarization present an innovative repair strategy for chronic wounds. 
Biological materials not only have the ability of immunological regulation, but also serve as carriers of cells and active molecules to enhance survival rates of transplanted cells and avoid the burst release of active molecules and rapid degradation. Therefore, combining the above-mentioned immunomodulatory biomaterials with active molecules that promote the polarization of macrophages to M2 phenotype may achieve a better pro-healing function than using materials or cells or active molecules alone. An increasing body of evidence points to the benefits of such approaches in inert implants (189, 194). Bioactive molecules or cells have been pursued to enhance wound repair, and they have been successfully administered through the different delivery systems, such as sponge scaffolds (195, 196), polymer (197, 198), hydrogel (199-201), and nanofibers $(202,203)$, which prove to be effective in preclinical studies.

Notably, increasing evidence reveals the immunomodulatory effects of biomaterials, which may become important approaches of treating chronic wounds, while the mechanism responsible for this response has rarely been explored. In future research, a large number of studies are required to examine the potential mechanism of immunomodulatory materials, and offers guidance for the design of more desirable biological materials to improve tissue repair and regeneration.

\section{PERSPECTIVES}

Based on this evidence, focus on the restoration of normal conversion of M1/M2 macrophage phenotypes is beneficial to proper wound healing. Notably, the therapeutic perspective and specific signal targets differ in the existing methods. We consider using existing multiple treatments in combination to achieve synergistic effects between each other, striving for the better therapeutic effects for the treatment of chronic wounds. Arguably, this is insufficient. The development of macrophagespecific pro-healing strategies is only the beginning. Several issues remain to be explored, including the modulation of macrophage activation and resolution of inflammation, the heterogeneity of the macrophage and discovery of novel subpopulations during the repair process, biological functions of individual macrophage lineages and the interaction mode between each subgroup or between each subgroup and other repair cells, and the understanding of the individual cues that can manipulate this heterogeneity. More importantly, specific molecular targets capable of repairing or restoring dysfunctional macrophages must also be intensively investigated. Novel technical approaches may be expected to solve these problems and find possible answers.

Advances in single cell RNA-sequencing (scRNA-Seq) offer an unprecedented approach for its power in monitoring the temporal evolution of heterogeneity and helping to identify novel cell subpopulations and unveil cellular interactions $(204,205)$. This methodology is increasingly employed in fields such as stem cell biology and oncology, while its applications in wound repair are still limited. Lately, Haensel et al. used scRNA-Seq analysis to identify epidermal hierarchical-lineage and transitional states during normal homeostasis and wound healing (206). Furthermore, Mahmoudi et al. revealed that the distinct subpopulations of fibroblasts with different cytokine expression and signaling in the wounds of old mice compared with young mice (207). Guerrero-Juarez et al. reported that fibroblasts, a major type of repair cells in wounds, grouped into twelve subsets, which demonstrated the high degree of heterogeneity among fibroblasts (208). Moreover, one cluster of fibroblasts might

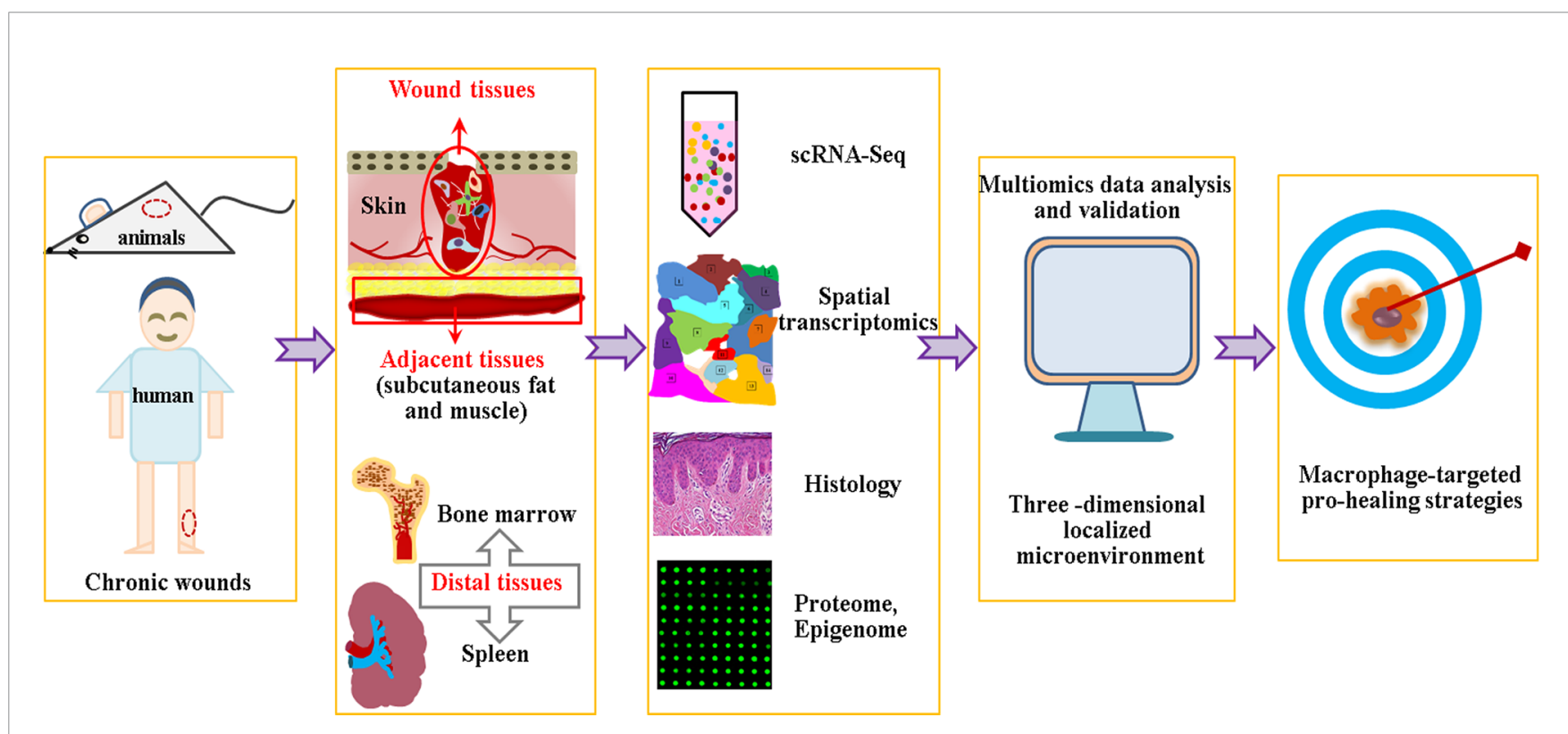

FIGURE 3 | Multiomics data analysis based macrophage specific therapy. 
originate from myeloid cells, according to the lineage tracing experiments. These results suggest the possibility and importance of scRNA-Seq technology as a unique tool for the better understanding of chronic wounds and therefore the development of macrophage-specific pro-healing strategies.

Certain limitations remain in the scRNA-Seq technology, including dropout events caused by the low detection efficiency of non-coding RNA or the failure of amplification of the original RNA transcripts (209-211), which may lead to misinterpretation of data in the downstream analysis. Novel single-cell transcriptome profiling or unique computational method must be developed to address this problem. Another issue is scRNA-Seq deciphering at a transcriptome level, as it is difficult to examine the abundance and post-translation of proteins, or provide spatial information of individual cells. The integrative analysis of multiomics data, such as scRNA-seq, spatial transcriptomics, proteome, histology and epigenome, etc., is to build a three -dimensional localized microenvironment conducive to resolve this question (212). An additional problem is the integration principle, as the occurrence of chronic wounds is affected by both local and systemic factors. Hence, we must not only pay attention to the local pathophysiology of chronic wounds, but also concern ourselves with adjacent tissues, such as subcutaneous adipose tissue or muscle, as adipocytes are important participants in hair follicle regeneration $(213,214)$. Furthermore, researchers must also focus on the pathophysiology of distal tissues, as aging and diabetes are accompanied by the abnormal output and function of immune and stem cells (215-218) (Figure 3).

\section{CONCLUSION}

Macrophages play essential roles in the persistence of the initial inflammatory process in chronic wounds. Hence, the treatment of chronic wounds lies in immunomodulation. Sustained increase in the number of wound macrophages and impairment of phenotypic switching are caused both by

\section{REFERENCES}

1. Liu ZJ, Velazquez OC. Hyperoxia, Endothelial Progenitor Cell Mobilization, and Diabetic Wound Healing. Antioxid Redox Signal (2008) 10:1869-82. doi: 10.1089/ars.2008.2121

2. Barman PK, Koh TJ. Macrophage Dysregulation and Impaired Skin Wound Healing in Diabetes. Front Cell Dev Biol (2020) 8:528. doi: 10.3389/ fcell.2020.00528

3. Eming SA, Wynn TA, Martin P. Inflammation and Metabolism in Tissue Repair and Regeneration. Science (2017) 356:1026-30. doi: 10.1126/science.aam7928

4. Koh TJ, DiPietro LA. Inflammation and Wound Healing: The Role of the Macrophage. Expert Rev Mol Med (2011) 13:e23. doi: 10.1017/S1462399411001943

5. Italiani P, Boraschi D. From Monocytes to M1/M2 Macrophages: Phenotypical vs. Functional Differentiation. Front Immunol (2014) 5:514. doi: 10.3389/ fimmu.2014.00514

6. Wynn TA, Vannella KM. Macrophages in Tissue Repair, Regeneration, and Fibrosis. Immunity (2016) 44:450-62. doi: 10.1016/j.immuni.2016.02.015

7. Eming SA, Krieg T, Davidson JM. Inflammation in Wound Repair: Molecular and Cellular Mechanisms. J Invest Dermatol (2007) 127:514-25. doi: 10.1038/ sj.jid.5700701 intrinsic alterations of HSPCs and an imbalanced wound microenvironment, which suggests that the treatment of chronic wounds requires consideration of multiple factors. Furthermore, high-throughput methods are a favorable tool to investigate the pathogenesis in detail and discover new targets, although their results require further validation. Moreover, it is a remarkable fact that there are differences in the thickness and number of cells between mouse and human skin, suggesting that skin wound healing in mice may differ from that in humans. Macrophage surface markers have been shown to differ in mice and humans (219). These variations make murine system difficult to translate to human conditions. In future studies, it is necessary to further validate prospective studies in humans to fill the gaps between pre-clinical and clinical studies.

\section{AUTHOR CONTRIBUTIONS}

ML: Writing-reviewing and editing. QH: Literature investigation and collation. LZ: Literature investigation and collation. YZ: Pictures in the article. XF: Conceptualization. All authors contributed to the article and approved the submitted version.

\section{FUNDING}

This study was supported in part by the National Nature Science Foundation of China (81971841, 81830064, 81721092, 81941021, 81901973), the National Key Research and Development Plan (2017YFC1104701, 2017YFC1103304, 2018YFC2000400), the CAMS Innovation Fund for Medical Sciences (CIFMS, 2019I2M-5-059) and the Military Medical Research and Development Projects (AWS17J005, 2019-126). The National S\&T Resource Sharing service platform Project of China (YCZYPT[2018]07), and the General Hospital of PLA Medical Big Data R\&D Project (MBD2018030).
8. Eming SA, Martin P, Tomic-Canic M. Wound Repair and Regeneration: Mechanisms, Signaling, and Translation. Sci Transl Med (2014) 6:265sr6. doi: 10.1126/scitranslmed.3009337

9. Singer AJ, Clark RA. Cutaneous Wound Healing. N Engl J Med (1999) 341:73846. doi: 10.1056/NEJM199909023411006

10. Krzyszczyk P, Schloss R, Palmer A, Berthiaume F. The Role of Macrophages in Acute and Chronic Wound Healing and Interventions to Promote Pro-Wound Healing Phenotypes. Front Physiol (2018) 9:419. doi: 10.3389/fphys.2018.00419

11. Zhao R, Liang H, Clarke E, Jackson C, Xue M. Inflammation in Chronic Wounds. Int J Mol Sci (2016) 18:1359. doi: 10.3390/ijms17122085

12. Gu S, Dai H, Zhao X, Gui C, Gui J. AKT3 Deficiency in M2 Macrophages Impairs Cutaneous Wound Healing by Disrupting Tissue Remodeling. Aging (Albany NY) (2020) 12:6928-46. doi: 10.18632/aging.103051

13. Sun H, Pulakat L, Anderson DW. Challenges and New Therapeutic Approaches in the Management of Chronic Wounds. Curr Drug Targets (2020) 21:1264-75. doi: 10.2174/1389450121666200623131200

14. Las Heras K, Igartua M, Santos-Vizcaino E, Hernandez RM. Chronic Wounds: Current Status, Available Strategies and Emerging Therapeutic Solutions. J Control Release (2020) 328:532-50. doi: 10.1016/j.jconrel. 2020.09.039 
15. Frykberg RG, Banks J. Challenges in the Treatment of Chronic Wounds. Adv Wound Care (New Rochelle) (2015) 4:560-82. doi: 10.1089/wound.2015.0635

16. Lewis J, Lipp A. Pressure-Relieving Interventions for Treating Diabetic Foot Ulcers. Cochrane Database Syst Rev (2013), CD002302. doi: 10.1002/ 14651858.CD002302.pub2

17. Holl J, Kowalewski C, Zimek Z, Fiedor P, Kaminski A, Oldak T, et al. Chronic Diabetic Wounds and Their Treatment With Skin Substitutes. Cells (2021) 10:655. doi: 10.3390/cells10030655

18. Boniakowski AE, Kimball AS, Jacobs BN, Kunkel SL, Gallagher KA. Macrophage-Mediated Inflammation in Normal and Diabetic Wound Healing. J Immunol (2017) 199:17-24. doi: 10.4049/jimmunol.1700223

19. Murray PJ, Allen JE, Biswas SK, Fisher EA, Gilroy DW, Goerdt S, et al. Macrophage Activation and Polarization: Nomenclature and Experimental Guidelines. Immunity (2014) 41:14-20. doi: 10.1016/j.immuni.2014.06.008

20. Sindrilaru A, Peters T, Wieschalka S, Baican C, Baican A, Peter H, et al. An Unrestrained Proinflammatory M1 Macrophage Population Induced by Iron Impairs Wound Healing in Humans and Mice. J Clin Invest (2011) 121:98597. doi: $10.1172 /$ JCI44490

21. Martinez FO, Gordon S. The M1 and M2 Paradigm of Macrophage Activation: Time for Reassessment. F1000Prime Rep (2014) 6:13. doi: 10.12703/P6-13

22. DiPietro LA, Wilgus TA, Koh TJ. Macrophages in Healing Wounds: Paradoxes and Paradigms. Int J Mol Sci (2021) 22:950. doi: 10.3390/ ijms22020950

23. Hadrian K, Willenborg S, Bock F, Cursiefen C, Eming SA, Hos D. Macrophage-Mediated Tissue Vascularization: Similarities and Differences Between Cornea and Skin. Front Immunol (2021) 12:667830. doi: 10.3389/ fimmu.2021.667830

24. Das A, Sinha M, Datta S, Abas M, Chaffee S, Sen CK, et al. Monocyte and Macrophage Plasticity in Tissue Repair and Regeneration. Am J Pathol (2015) 185:2596-606. doi: 10.1016/j.ajpath.2015.06.001

25. Khanna S, Biswas S, Shang Y, Collard E, Azad A, Kauh C, et al. Macrophage Dysfunction Impairs Resolution of Inflammation in the Wounds of Diabetic Mice. PloS One (2010) 5:e9539. doi: 10.1371/journal.pone.0009539

26. Davies LC, Taylor PR. Tissue-Resident Macrophages: Then and Now. Immunology (2015) 144:541-8. doi: 10.1111/imm.12451

27. Li N, Chen J, Wang P, Fan H, Hou S, Gong Y. Major Signaling Pathways and Key Mediators of Macrophages in Acute Kidney Injury (Review). Mol Med Rep (2021) 23:455. doi: 10.3892/mmr.2021.12094

28. Ummarino A, Gambaro FM, Kon E, Torres Andon F. Therapeutic Manipulation of Macrophages Using Nanotechnological Approaches for the Treatment of Osteoarthritis. Nanomater (Basel) (2020) 10:1562. doi: 10.3390/ nano10081562

29. Burgess M, Wicks K, Gardasevic M, Mace KA. Cx3CR1 Expression Identifies Distinct Macrophage Populations That Contribute Differentially to Inflammation and Repair. Immunohorizons (2019) 3:262-73. doi: 10.4049/ immunohorizons. 1900038

30. Davies LC, Jenkins SJ, Allen JE, Taylor PR. Tissue-Resident Macrophages. Nat Immunol (2013) 14:986-95. doi: 10.1038/ni.2705

31. Malissen B, Tamoutounour S, Henri S. The Origins and Functions of Dendritic Cells and Macrophages in the Skin. Nat Rev Immunol (2014) 14:417-28. doi: 10.1038/nri3683

32. Goren I, Allmann N, Yogev N, Schurmann C, Linke A, Holdener M, et al. A Transgenic Mouse Model of Inducible Macrophage Depletion: Effects of Diphtheria Toxin-Driven Lysozyme M-Specific Cell Lineage Ablation on Wound Inflammatory, Angiogenic, and Contractive Processes. Am J Pathol (2009) 175:132-47. doi: 10.2353/ajpath.2009.081002

33. Mirza R, DiPietro LA, Koh TJ. Selective and Specific Macrophage Ablation Is Detrimental to Wound Healing in Mice. Am J Pathol (2009) 175:2454-62. doi: 10.2353/ajpath.2009.090248

34. Lucas T, Waisman A, Ranjan R, Roes J, Krieg T, Muller W, et al. Differential Roles of Macrophages in Diverse Phases of Skin Repair. J Immunol (2010) 184:3964-77. doi: 10.4049/jimmunol.0903356

35. Varela P, Sartori S, Viebahn R, Salber J, Ciardelli G. Macrophage Immunomodulation: An Indispensable Tool to Evaluate the Performance of Wound Dressing Biomaterials. J Appl Biomater Funct Mater (2019) 17:2280800019830355. doi: 10.1177/2280800019830355
36. Minutti CM, Knipper JA, Allen JE, Zaiss DM. Tissue-Specific Contribution of Macrophages to Wound Healing. Semin Cell Dev Biol (2017) 61:3-11. doi: 10.1016/j.semcdb.2016.08.006

37. Xu Q, Choksi S, Qu J, Jang J, Choe M, Banfi B, et al. Nadph Oxidases Are Essential for Macrophage Differentiation. J Biol Chem (2016) 291:20030-41. doi: 10.1074/jbc.M116.731216

38. Kotwal GJ, Chien S. Macrophage Differentiation in Normal and Accelerated Wound Healing. Results Probl Cell Differ (2017) 62:353-64. doi: 10.1007/9783-319-54090-0_14

39. Yu H, Xiong J, Qiu J, He X, Sheng H, Dai Q, et al. Type III Secretion Protein, Pcrv, Impairs Pseudomonas Aeruginosa Biofilm Formation by Increasing M1 Macrophage-Mediated Anti-Bacterial Activities. Front Microbiol (2020) 11:1971. doi: $10.3389 /$ fmicb.2020.01971

40. Keewan E, Naser SA. The Role of Notch Signaling in Macrophages During Inflammation and Infection: Implication in Rheumatoid Arthritis? Cells (2020) 9:111. doi: 10.3390/cells9010111

41. Spiller KL, Anfang RR, Spiller KJ, Ng J, Nakazawa KR, Daulton JW, et al. The Role of Macrophage Phenotype in Vascularization of Tissue Engineering Scaffolds. Biomaterials (2014) 35:4477-88. doi: 10.1016/j.biomaterials. 2014.02.012

42. Kimball A, Schaller M, Joshi A, Davis FM, denDekker A, Boniakowski A, et al. Ly6c(Hi) Blood Monocyte/Macrophage Drive Chronic Inflammation and Impair Wound Healing in Diabetes Mellitus. Arterioscler Thromb Vasc Biol (2018) 38:1102-14. doi: 10.1161/ATVBAHA.118.310703

43. Mirza RE, Fang MM, Ennis WJ, Koh TJ. Blocking Interleukin-1beta Induces a Healing-Associated Wound Macrophage Phenotype and Improves Healing in Type 2 Diabetes. Diabetes (2013) 62:2579-87. doi: 10.2337/db12-1450

44. Mirza RE, Fang MM, Weinheimer-Haus EM, Ennis WJ, Koh TJ. Sustained Inflammasome Activity in Macrophages Impairs Wound Healing in Type 2 Diabetic Humans and Mice. Diabetes (2014) 63:1103-14. doi: 10.2337/db13-0927

45. Willenborg S, Lucas T, van Loo G, Knipper JA, Krieg T, Haase I, et al. CCR2 Recruits an Inflammatory Macrophage Subpopulation Critical for Angiogenesis in Tissue Repair. Blood (2012) 120:613-25. doi: 10.1182/ blood-2012-01-403386

46. Ferrante CJ, Leibovich SJ. Regulation of Macrophage Polarization and Wound Healing. Adv Wound Care (New Rochelle) (2012) 1:10-6. doi: 10.1089/ wound.2011.0307

47. Novak ML, Koh TJ. Macrophage Phenotypes During Tissue Repair. J Leukoc Biol (2013) 93:875-81. doi: 10.1189/jlb.1012512

48. Grinberg S, Hasko G, Wu D, Leibovich SJ. Suppression of PLCbeta2 by Endotoxin Plays a Role in the Adenosine A(2A) Receptor-Mediated Switch of Macrophages From An Inflammatory to An Angiogenic Phenotype. Am J Pathol (2009) 175:2439-53. doi: 10.2353/ajpath.2009.090290

49. Hesketh M, Sahin KB, West ZE, Murray RZ. Macrophage Phenotypes Regulate Scar Formation and Chronic Wound Healing. Int J Mol Sci (2017) 18:1545. doi: $10.3390 /$ ijms 18071545

50. Xu X, Gu S, Huang X, Ren J, Gu Y, Wei C, et al. The Role of Macrophages in the Formation of Hypertrophic Scars and Keloids. Burns Trauma (2020) 8: tkaa006. doi: 10.1093/burnst/tkaa006

51. Gratchev A, Guillot P, Hakiy N, Politz O, Orfanos CE, Schledzewski K, et al. Alternatively Activated Macrophages Differentially Express Fibronectin and Its Splice Variants and the Extracellular Matrix Protein Betaig-H3. Scand J Immunol (2001) 53:386-92. doi: 10.1046/j.1365-3083.2001.00885.x

52. Mahdavian Delavary B, van der Veer WM, van Egmond M, Niessen FB, Beelen RH. Macrophages in Skin Injury and Repair. Immunobiology (2011) 216:753-62. doi: 10.1016/j.imbio.2011.01.001

53. Weidenbusch M, Anders HJ. Tissue Microenvironments Define and Get Reinforced by Macrophage Phenotypes in Homeostasis or During Inflammation, Repair and Fibrosis. J Innate Immun (2012) 4:463-77. doi: $10.1159 / 000336717$

54. Lurier EB, Dalton D, Dampier W, Raman P, Nassiri S, Ferraro NM, et al. Transcriptome Analysis of IL-10-Stimulated (M2c) Macrophages by NextGeneration Sequencing. Immunobiology (2017) 222:847-56. doi: 10.1016/ j.imbio.2017.02.006

55. Edwards JP, Zhang X, Frauwirth KA, Mosser DM. Biochemical and Functional Characterization of Three Activated Macrophage Populations. J Leukoc Biol (2006) 80:1298-307. doi: 10.1189/jlb.0406249 
56. Gerber JS, Mosser DM. Reversing Lipopolysaccharide Toxicity by Ligating the Macrophage Fc Gamma Receptors. J Immunol (2001) 166:6861-8. doi: 10.4049/jimmunol.166.11.6861

57. Yue Y, Huang S, Wu Z, Wang K, Li H, Hou J, et al. Characterization of mRNA Profiles of Exosomes From Diverse Forms of M2 Macrophages. BioMed Res Int (2020) 2020:1585306. doi: 10.1155/2020/1585306

58. Melton DW, McManus LM, Gelfond JA, Shireman PK. Temporal Phenotypic Features Distinguish Polarized Macrophages In Vitro. Autoimmunity (2015) 48:161-76. doi: 10.3109/08916934.2015.1027816

59. Roszer T. Understanding the Mysterious M2 Macrophage Through Activation Markers and Effector Mechanisms. Mediators Inflamm (2015) 2015:816460. doi: $10.1155 / 2015 / 816460$

60. Tenspolde M, Zimmermann K, Weber LC, Hapke M, Lieber M, Dywicki J, et al. Regulatory T Cells Engineered With a Novel Insulin-Specific Chimeric Antigen Receptor as a Candidate Immunotherapy for Type 1 Diabetes. J Autoimmun (2019) 103:102289. doi: 10.1016/j.jaut.2019.05.017

61. Jetten N, Verbruggen S, Gijbels MJ, Post MJ, De Winther MP, Donners MM. Anti-Inflammatory M2, But Not Pro-Inflammatory M1 Macrophages Promote Angiogenesis In Vivo. Angiogenesis (2014) 17:109-18. doi: 10.1007/s10456-013-9381-6

62. Fuchs E, Blau HM. Tissue Stem Cells: Architects of Their Niches. Cell Stem Cell (2020) 27:532-56. doi: 10.1016/j.stem.2020.09.011

63. Jaukovic A, Kukolj T, Obradovic H, Okic-Dordevic I, Mojsilovic S, Bugarski D. Inflammatory Niche: Mesenchymal Stromal Cell Priming by Soluble Mediators. World J Stem Cells (2020) 12:922-37. doi: 10.4252/wjsc.v12.i9.922

64. Silva WN, Prazeres P, Paiva AE, Lousado L, Turquetti AOM, Barreto RSN, et al. Macrophage-Derived GPNMB Accelerates Skin Healing. Exp Dermatol (2018) 27:630-5. doi: 10.1111/exd.13524

65. Yu B, Alboslemy T, Safadi F, Kim MH. Glycoprotein Nonmelanoma Clone B Regulates the Crosstalk Between Macrophages and Mesenchymal Stem Cells Toward Wound Repair. J Invest Dermatol (2018) 138:219-27. doi: 10.1016/ j.jid.2017.08.034

66. Lolmede K, Campana L, Vezzoli M, Bosurgi L, Tonlorenzi R, Clementi E, et al. Inflammatory and Alternatively Activated Human Macrophages Attract Vessel-Associated Stem Cells, Relying on Separate HMGB1- and MMP-9Dependent Pathways. J Leukoc Biol (2009) 85:779-87. doi: 10.1189/ jlb.0908579

67. Kim SY, Nair MG. Macrophages in Wound Healing: Activation and Plasticity. Immunol Cell Biol (2019) 97:258-67. doi: 10.1111/imcb.12236

68. Mantovani A, Sica A, Sozzani S, Allavena P, Vecchi A, Locati M. The Chemokine System in Diverse Forms of Macrophage Activation and Polarization. Trends Immunol (2004) 25:677-86. doi: 10.1016/j.it.2004.09.015

69. Madsen DH, Leonard D, Masedunskas A, Moyer A, Jurgensen HJ, Peters DE, et al. M2-Like Macrophages Are Responsible for Collagen Degradation Through a Mannose Receptor-Mediated Pathway. J Cell Biol (2013) 202:951-66. doi: 10.1083/jcb.201301081

70. Castellana D, Paus R, Perez-Moreno M. Macrophages Contribute to the Cyclic Activation of Adult Hair Follicle Stem Cells. PloS Biol (2014) 12:e1002002. doi: 10.1371/journal.pbio. 1002002

71. Stenn KS, Paus R. Controls of Hair Follicle Cycling. Physiol Rev (2001) 81:449-94. doi: 10.1152/physrev.2001.81.1.449

72. Martinot V, Mitchell V, Fevrier P, Duhamel A, Pellerin P. Comparative Study of Split Thickness Skin Grafts Taken From the Scalp and Thigh in Children. Burns (1994) 20:146-50. doi: 10.1016/S0305-4179(06)80012-4

73. Chu SY, Chou CH, Huang HD, Yen MH, Hong HC, Chao PH, et al. Mechanical Stretch Induces Hair Regeneration Through the Alternative Activation of Macrophages. Nat Commun (2019) 10:1524. doi: 10.1038/ s41467-019-09402-8

74. Wang X, Chen $\mathrm{H}$, Tian R, Zhang Y, Drutskaya MS, Wang C, et al. Macrophages Induce AKT/beta-catenin-Dependent Lgr5(+) Stem Cell Activation and Hair Follicle Regeneration Through TNF. Nat Commun (2017) 8:14091. doi: 10.1038/ncomms14091

75. Osaka N, Takahashi T, Murakami S, Matsuzawa A, Noguchi T, Fujiwara T, et al. ASK1-Dependent Recruitment and Activation of Macrophages Induce Hair Growth in Skin Wounds. J Cell Biol (2007) 176:903-9. doi: 10.1083/jcb.200611015

76. Bystrom J, Evans I, Newson J, Stables M, Toor I, van Rooijen N, et al. Resolution-Phase Macrophages Possess a Unique Inflammatory Phenotype
That Is Controlled by Camp. Blood (2008) 112:4117-27. doi: 10.1182/blood2007-12-129767

77. Porcheray F, Viaud S, Rimaniol AC, Leone C, Samah B, Dereuddre-Bosquet $\mathrm{N}$, et al. Macrophage Activation Switching: An Asset for the Resolution of Inflammation. Clin Exp Immunol (2005) 142:481-9. doi: 10.1111/j.13652249.2005.02934.x

78. Sica A, Mantovani A. Macrophage Plasticity and Polarization: In Vivo Veritas. J Clin Invest (2012) 122:787-95. doi: 10.1172/JCI59643

79. Cucak H, Grunnet LG, Rosendahl A. Accumulation of M1-Like Macrophages in Type 2 Diabetic Islets Is Followed by a Systemic Shift in Macrophage Polarization. J Leukoc Biol (2014) 95:149-60. doi: 10.1189/jlb.0213075

80. Sica A, Erreni M, Allavena P, Porta C. Macrophage Polarization in Pathology. Cell Mol Life Sci (2015) 72:4111-26. doi: 10.1007/s00018-015-1995-y

81. Esser N, Legrand-Poels S, Piette J, Scheen AJ, Paquot N. Inflammation as a Link Between Obesity, Metabolic Syndrome and Type 2 Diabetes. Diabetes Res Clin Pract (2014) 105:141-50. doi: 10.1016/j.diabres.2014.04.006

82. Salminen A. Increased Immunosuppression Impairs Tissue Homeostasis With Aging and Age-Related Diseases. J Mol Med (Berl) (2020) 99:1-20. doi: 10.1007/s00109-020-01988-7

83. Basu Mallik S, Jayashree BS, Shenoy RR. Epigenetic Modulation of Macrophage Polarization- Perspectives in Diabetic Wounds. J Diabetes Complicat (2018) 32:524-30. doi: 10.1016/j.jdiacomp.2018.01.015

84. Lee JM, Govindarajah V, Goddard B, Hinge A, Muench DE, Filippi MD, et al. Obesity Alters the Long-Term Fitness of the Hematopoietic Stem Cell Compartment Through Modulation of Gfil Expression. J Exp Med (2018) 215:627-44. doi: 10.1084/jem.20170690

85. Adler BJ, Kaushansky K, Rubin CT. Obesity-Driven Disruption of Haematopoiesis and the Bone Marrow Niche. Nat Rev Endocrinol (2014) 10:737-48. doi: 10.1038/nrendo.2014.169

86. Nagareddy PR, Kraakman M, Masters SL, Stirzaker RA, Gorman DJ, Grant RW, et al. Adipose Tissue Macrophages Promote Myelopoiesis and Monocytosis in Obesity. Cell Metab (2014) 19:821-35. doi: 10.1016/ j.cmet.2014.03.029

87. Akunuru S, Geiger H. Aging, Clonality, and Rejuvenation of Hematopoietic Stem Cells. Trends Mol Med (2016) 22:701-12. doi: 10.1016/j.molmed. 2016.06.003

88. Rossi DJ, Bryder D, Zahn JM, Ahlenius H, Sonu R, Wagers AJ, et al. Cell Intrinsic Alterations Underlie Hematopoietic Stem Cell Aging. Proc Natl Acad Sci USA (2005) 102:9194-9. doi: 10.1073/pnas.0503280102

89. Ergen AV, Boles NC, Goodell MA. Rantes/Ccl5 Influences Hematopoietic Stem Cell Subtypes and Causes Myeloid Skewing. Blood (2012) 119:2500-9. doi: 10.1182/blood-2011-11-391730

90. Krensky AM, Ahn YT. Mechanisms of Disease: Regulation of RANTES (CCL5) in Renal Disease. Nat Clin Pract Nephrol (2007) 3:164-70. doi: 10.1038/ncpneph0418

91. Bharath LP, Ip BC, Nikolajczyk BS. Adaptive Immunity and Metabolic Health: Harmony Becomes Dissonant in Obesity and Aging. Compr Physiol (2017) 7:1307-37. doi: 10.1002/cphy.c160042

92. Frasca D, Blomberg BB. Adipose Tissue, Immune Aging, and Cellular Senescence. Semin Immunopathol (2020) 42:573-87. doi: 10.1007/s00281-020-00812-1

93. Naveiras O, Nardi V, Wenzel PL, Hauschka PV, Fahey F, Daley GQ. BoneMarrow Adipocytes as Negative Regulators of the Haematopoietic Microenvironment. Nature (2009) 460:259-63. doi: 10.1038/nature08099

94. Gallagher KA, Joshi A, Carson WF, Schaller M, Allen R, Mukerjee S, et al. Epigenetic Changes in Bone Marrow Progenitor Cells Influence the Inflammatory Phenotype and Alter Wound Healing in Type 2 Diabetes. Diabetes (2015) 64:1420-30. doi: 10.2337/db14-0872

95. Barman PK, Urao N, Koh TJ. Diabetes Induces Myeloid Bias in Bone Marrow Progenitors Associated With Enhanced Wound Macrophage Accumulation and Impaired Healing. J Pathol (2019) 249:435-46. doi: 10.1002/path.5330

96. Singer K, DelProposto J, Morris DL, Zamarron B, Mergian T, Maley N, et al. Diet-Induced Obesity Promotes Myelopoiesis in Hematopoietic Stem Cells. Mol Metab (2014) 3:664-75. doi: 10.1016/j.molmet.2014.06.005

97. van den Berg SM, Seijkens TT, Kusters PJ, Beckers L, den Toom M, Smeets E, et al. Diet-Induced Obesity in Mice Diminishes Hematopoietic Stem and Progenitor Cells in the Bone Marrow. FASEB J (2016) 30:1779-88. doi: 10.1096/fj.201500175 
98. Nagareddy PR, Murphy AJ, Stirzaker RA, Hu Y, Yu S, Miller RG, et al. Hyperglycemia Promotes Myelopoiesis and Impairs the Resolution of Atherosclerosis. Cell Metab (2013) 17:695-708. doi: 10.1016/j.cmet. 2013.04.001

99. Vasamsetti SB, Florentin J, Coppin E, Stiekema LCA, Zheng KH, Nisar MU, et al. Sympathetic Neuronal Activation Triggers Myeloid Progenitor Proliferation and Differentiation. Immunity (2018) 49:93-106 e7. doi: 10.1016/j.immuni.2018.05.004

100. Yan J, Tie G, Wang S, Tutto A, DeMarco N, Khair L, et al. Diabetes Impairs Wound Healing by Dnmt1-Dependent Dysregulation of Hematopoietic Stem Cells Differentiation Towards Macrophages. Nat Commun (2018) 9:33. doi: 10.1038/s41467-017-02425-z

101. Wood S, Jayaraman V, Huelsmann EJ, Bonish B, Burgad D, Sivaramakrishnan G, et al. Pro-Inflammatory Chemokine CCL2 (Mcp-1) Promotes Healing in Diabetic Wounds by Restoring the Macrophage Response. PloS One (2014) 9:e91574. doi: 10.1371/journal.pone.0091574

102. Mirza RE, Fang MM, Novak ML, Urao N, Sui A, Ennis WJ, et al. Macrophage PPARgamma and Impaired Wound Healing in Type 2 Diabetes. J Pathol (2015) 236:433-44. doi: 10.1002/path.4548

103. Roch T, Akymenko O, Kruger A, Jung F, Ma N, Lendlein A. Expression Pattern Analysis and Activity Determination of Matrix Metalloproteinase Derived From Human Macrophage Subsets. Clin Hemorheol Microcirc (2014) 58:147-58. doi: 10.3233/CH-141885

104. Demaria M, Ohtani N, Youssef SA, Rodier F, Toussaint W, Mitchell JR, et al. An Essential Role for Senescent Cells in Optimal Wound Healing Through Secretion of PDGF-AA. Dev Cell (2014) 31:722-33. doi: 10.1016/j.devcel.2014.11.012

105. Jun JI, Lau LF. Cellular Senescence Controls Fibrosis in Wound Healing. Aging (Albany NY) (2010) 2:627-31. doi: 10.18632/aging.100201

106. Yun MH, Davaapil H, Brockes JP. Recurrent Turnover of Senescent Cells During Regeneration of A Complex Structure. Elife (2015) 4:e05505. doi: 10.7554/eLife. 05505

107. Tomic-Canic M, DiPietro LA. Cellular Senescence in Diabetic Wounds: When Too Many Retirees Stress the System. J Invest Dermatol (2019) 139:997-9. doi: 10.1016/j.jid.2019.02.019

108. Wilkinson HN, Clowes C, Banyard KL, Matteuci P, Mace KA, Hardman MJ. Elevated Local Senescence in Diabetic Wound Healing is Linked to Pathological Repair Via CXCR2. J Invest Dermatol (2019) 139:1171-81 e6. doi: 10.1016/j.jid.2019.01.005

109. Song P, Zhao Q, Zou MH. Targeting Senescent Cells to Attenuate Cardiovascular Disease Progression. Ageing Res Rev (2020) 60:101072. doi: 10.1016/j.arr.2020.101072

110. Baker DJ, Petersen RC. Cellular Senescence in Brain Aging and Neurodegenerative Diseases: Evidence and Perspectives. J Clin Invest (2018) 128:1208-16. doi: 10.1172/JCI95145

111. Frasca D. Senescent B Cells in Aging and Age-Related Diseases: Their Role in the Regulation of Antibody Responses. Exp Gerontol (2018) 107:55-8. doi: 10.1016/j.exger.2017.07.002

112. Aguayo-Mazzucato C, Andle J, Lee TBJr., Midha A, Talemal L, Chipashvili V, et al. Acceleration of Beta Cell Aging Determines Diabetes and Senolysis Improves Disease Outcomes. Cell Metab (2019) 30:129-42.e4. doi: 10.1016/ j.cmet.2019.05.006

113. Stout MB, Justice JN, Nicklas BJ, Kirkland JL. Physiological Aging: Links Among Adipose Tissue Dysfunction, Diabetes, and Frailty. Physiol (Bethesda) (2017) 32:9-19. doi: 10.1152/physiol.00012.2016

114. Chen H, Shi R, Luo B, Yang X, Qiu L, Xiong J, et al. Macrophage Peroxisome Proliferator-Activated Receptor Gamma Deficiency Delays Skin Wound Healing Through Impairing Apoptotic Cell Clearance in Mice. Cell Death Dis (2015) 6:e1597. doi: 10.1038/cddis.2014.544

115. Huang SM, Wu CS, Chiu MH, Wu CH, Chang YT, Chen GS, et al. High Glucose Environment Induces M1 Macrophage Polarization That Impairs Keratinocyte Migration Via TNF-alpha: An Important Mechanism to Delay the Diabetic Wound Healing. J Dermatol Sci (2019) 96:159-67. doi: 10.1016/ j.jdermsci.2019.11.004

116. Murata Y, Shimamura T, Hamuro J. The Polarization of $\mathrm{T}(\mathrm{h}) 1 / \mathrm{T}(\mathrm{h}) 2$ Balance Is Dependent on the Intracellular Thiol Redox Status of Macrophages Due to the Distinctive Cytokine Production. Int Immunol (2002) 14:201-12. doi: 10.1093/intimm/14.2.201
117. Tan HY, Wang N, Li S, Hong M, Wang X, Feng Y. The Reactive Oxygen Species in Macrophage Polarization: Reflecting Its Dual Role in Progression and Treatment of Human Diseases. Oxid Med Cell Longev (2016) 2016:2795090. doi: 10.1155/2016/2795090

118. Bezold V, Rosenstock P, Scheffler J, Geyer H, Horstkorte R, Bork K. Glycation of Macrophages Induces Expression of Pro-Inflammatory Cytokines and Reduces Phagocytic Efficiency. Aging (Albany NY) (2019) 11:5258-75. doi: 10.18632/aging.102123

119. He S, Hu Q, Xu X, Niu Y, Chen Y, Lu Y, et al. Advanced Glycation End Products Enhance M1 Macrophage Polarization by Activating the MAPK Pathway. Biochem Biophys Res Commun (2020) 525:334-40. doi: 10.1016/ j.bbrc.2020.02.053

120. Dinh T, Tecilazich F, Kafanas A, Doupis J, Gnardellis C, Leal E, et al. Mechanisms Involved in the Development and Healing of Diabetic Foot Ulceration. Diabetes (2012) 61:2937-47. doi: 10.2337/db12-0227

121. Gregor MF, Hotamisligil GS. Inflammatory Mechanisms in Obesity. Annu Rev Immunol (2011) 29:415-45. doi: 10.1146/annurev-immunol-031210101322

122. Ozcan U, Cao Q, Yilmaz E, Lee AH, Iwakoshi NN, Ozdelen E, et al. Endoplasmic Reticulum Stress Links Obesity, Insulin Action, and Type 2 Diabetes. Science (2004) 306:457-61. doi: 10.1126/science.1103160

123. Giordano A, Murano I, Mondini E, Perugini J, Smorlesi A, Severi I, et al. Obese Adipocytes Show Ultrastructural Features of Stressed Cells and Die of Pyroptosis. J Lipid Res (2013) 54:2423-36. doi: 10.1194/jlr.M038638

124. Dalmas E, Clement K, Guerre-Millo M. Defining Macrophage Phenotype and Function in Adipose Tissue. Trends Immunol (2011) 32:307-14. doi: 10.1016/j.it.2011.04.008

125. Leal EC, Carvalho E, Tellechea A, Kafanas A, Tecilazich F, Kearney C, et al. Substance P Promotes Wound Healing in Diabetes by Modulating Inflammation and Macrophage Phenotype. Am J Pathol (2015) 185:163848. doi: 10.1016/j.ajpath.2015.02.011

126. Pradhan L, Cai X, Wu S, Andersen ND, Martin M, Malek J, et al. Gene Expression of Pro-Inflammatory Cytokines and Neuropeptides in Diabetic Wound Healing. J Surg Res (2011) 167:336-42. doi: 10.1016/j.jss.2009.09.012

127. Pradhan Nabzdyk L, Kuchibhotla S, Guthrie P, Chun M, Auster ME, Nabzdyk C, et al. Expression of Neuropeptides and Cytokines in a Rabbit Model of Diabetic Neuroischemic Wound Healing. J Vasc Surg (2013) 58:766-75 e12. doi: 10.1016/j.jvs.2012.11.095

128. Chen S, Li R, Cheng C, Xu JY, Jin C, Gao F, et al. Pseudomonas Aeruginosa Infection Alters the Macrophage Phenotype Switching Process During Wound Healing in Diabetic Mice. Cell Biol Int (2018) 42:877-89. doi: 10.1002/cbin.10955

129. Ge Y, MacDonald D, Hait H, Lipsky B, Zasloff M, Holroyd K. Microbiological Profile of Infected Diabetic Foot Ulcers. Diabetes Med (2002) 19:1032-4. doi: 10.1046/j.1464-5491.2002.00696_1.x

130. Ramakant P, Verma AK, Misra R, Prasad KN, Chand G, Mishra A, et al. Changing Microbiological Profile of Pathogenic Bacteria in Diabetic Foot Infections: Time for a Rethink on Which Empirical Therapy to Choose? Diabetologia (2011) 54:58-64. doi: 10.1007/s00125-010-1893-7

131. Cavaillon JM. Exotoxins and Endotoxins: Inducers of Inflammatory Cytokines. Toxicon (2018) 149:45-53. doi: 10.1016/j.toxicon.2017.10.016

132. Goldufsky J, Wood SJ, Jayaraman V, Majdobeh O, Chen L, Qin S, et al. Pseudomonas Aeruginosa Uses T3SS to Inhibit Diabetic Wound Healing. Wound Repair Regener (2015) 23:557-64. doi: 10.1111/wrr.12310

133. Talamonti E, Pauter AM, Asadi A, Fischer AW, Chiurchiu V, Jacobsson A. Impairment of Systemic DHA Synthesis Affects Macrophage Plasticity and Polarization: Implications for DHA Supplementation During Inflammation. Cell Mol Life Sci (2017) 74:2815-26. doi: 10.1007/s00018-017-2498-9

134. Jia YC, Qiu S, Xu J, Kang QL, Chai YM. Docosahexaenoic Acid Improves Diabetic Wound Healing in a Rat Model by Restoring Impaired Plasticity of Macrophage Progenitor Cells. Plast Reconstr Surg (2020) 145:942e-50e. doi: 10.1097/PRS.0000000000006739

135. Nicklas BJ, You T, Pahor M. Behavioural Treatments for Chronic Systemic Inflammation: Effects of Dietary Weight Loss and Exercise Training. CMAJ (2005) 172:1199-209. doi: 10.1503/cmaj.1040769

136. Petersen EW, Carey AL, Sacchetti M, Steinberg GR, Macaulay SL, Febbraio MA, et al. Acute IL-6 Treatment Increases Fatty Acid Turnover in Elderly 
Humans In Vivo and in Tissue Culture In Vitro. Am J Physiol Endocrinol Metab (2005) 288:E155-62. doi: 10.1152/ajpendo.00257.2004

137. Bruun JM, Lihn AS, Pedersen SB, Richelsen B. Monocyte Chemoattractant Protein-1 Release Is Higher in Visceral Than Subcutaneous Human Adipose Tissue (AT): Implication of Macrophages Resident in the AT. J Clin Endocrinol Metab (2005) 90:2282-9. doi: 10.1210/jc.2004-1696

138. Weisberg SP, McCann D, Desai M, Rosenbaum M, Leibel RL, Ferrante AW Jr. Obesity Is Associated With Macrophage Accumulation in Adipose Tissue. J Clin Invest (2003) 112:1796-808. doi: 10.1172/JCI200319246

139. Mancuso P, Bouchard B. The Impact of Aging on Adipose Function and Adipokine Synthesis. Front Endocrinol (Lausanne) (2019) 10:137. doi: 10.3389/fendo.2019.00137

140. Rea IM, Gibson DS, McGilligan V, McNerlan SE, Alexander HD, Ross OA. Age and Age-Related Diseases: Role of Inflammation Triggers and Cytokines. Front Immunol (2018) 9:586. doi: 10.3389/fimmu.2018.00586

141. Goren I, Muller E, Schiefelbein D, Christen U, Pfeilschifter J, Muhl H, et al. Systemic anti-TNFalpha Treatment Restores Diabetes-Impaired Skin Repair in Ob/Ob Mice by Inactivation of Macrophages. J Invest Dermatol (2007) 127:2259-67. doi: 10.1038/sj.jid.5700842

142. Blakytny R, Jude E. The Molecular Biology of Chronic Wounds and Delayed Healing in Diabetes. Diabetes Med (2006) 23:594-608. doi: 10.1111/j.14645491.2006.01773.x

143. Hrabak A, Bajor T, Southan GJ, Salzman AL, Szabo C. Comparison of the Inhibitory Effect of Isothiourea and Mercapto-Alkylguanidine Derivatives on the Alternative Pathways of Arginine Metabolism in Macrophages. Life Sci (1997) 60:395-401. doi: 10.1016/S0024-3205(97)00328-7

144. Stempin CC, Dulgerian LR, Garrido VV, Cerban FM. Arginase in Parasitic Infections: Macrophage Activation, Immunosuppression, and Intracellular Signals. J BioMed Biotechnol (2010) 2010:683485. doi: 10.1155/2010/683485

145. Dixit R, Debnath A, Mishra S, Mishra R, Bhartiya SK, Pratap A, et al. A Study of Arginase Expression in Chronic Non-Healing Wounds. Int J Low Extrem Wounds (2021) 15347346211012381. doi: 10.1177/15347346211012381

146. Campbell L, Saville CR, Murray PJ, Cruickshank SM, Hardman MJ. Local Arginase 1 Activity is Required for Cutaneous Wound Healing. J Invest Dermatol (2013) 133:2461-70. doi: 10.1038/jid.2013.164

147. Kavalukas SL, Uzgare AR, Bivalacqua TJ, Barbul A. Arginase Inhibition Promotes Wound Healing in Mice. Surgery (2012) 151:287-95. doi: 10.1016/ j.surg.2011.07.012

148. Wang Q, Zhu G, Cao X, Dong J, Song F, Niu Y. Blocking AGE-RAGE Signaling Improved Functional Disorders of Macrophages in Diabetic Wound. J Diabetes Res (2017) 2017:1428537. doi: 10.1155/2017/1428537

149. Schultze JL, Schmieder A, Goerdt S. Macrophage Activation in Human Diseases. Semin Immunol (2015) 27:249-56. doi: 10.1016/j.smim.2015. 07.003

150. Zheng Y, Wang X, Ji S, Tian S, Wu H, Luo P, et al. Mepenzolate Bromide Promotes Diabetic Wound Healing by Modulating Inflammation and Oxidative Stress. Am J Transl Res (2016) 8:2738-47.

151. Dhall S, Do DC, Garcia M, Kim J, Mirebrahim SH, Lyubovitsky J, et al. Generating and Reversing Chronic Wounds in Diabetic Mice by Manipulating Wound Redox Parameters. J Diabetes Res (2014) 2014:562625. doi: 10.1155/2014/562625

152. Ali M, Bonay M, Vanhee V, Vinit S, Deramaudt TB. Comparative Effectiveness of 4 Natural and Chemical Activators of Nrf2 on Inflammation, Oxidative Stress, Macrophage Polarization, and Bactericidal Activity in an In Vitro Macrophage Infection Model. PloS One (2020) 15: e0234484. doi: 10.1371/journal.pone.0234484

153. Alvarado-Vazquez PA, Bernal L, Paige CA, Grosick RL, Moracho Vilrriales C, Ferreira DW, et al. Macrophage-Specific Nanotechnology-Driven CD163 Overexpression in Human Macrophages Results in an M2 Phenotype Under Inflammatory Conditions. Immunobiology (2017) 222:900-12. doi: 10.1016/ j.imbio.2017.05.011

154. Ferreira DW, Ulecia-Moron C, Alvarado-Vazquez PA, Cunnane K, Moracho-Vilriales C, Grosick RL, et al. CD163 Overexpression Using a Macrophage-Directed Gene Therapy Approach Improves Wound Healing in Ex Vivo and In Vivo Human Skin Models. Immunobiology (2020) 225:151862. doi: 10.1016/j.imbio.2019.10.011

155. Frenkel O, Shani E, Ben-Bassat I, Brok-Simoni F, Rozenfeld-Granot G, Kajakaro G, et al. Activated Macrophages for Treating Skin Ulceration: Gene
Expression in Human Monocytes After Hypo-Osmotic Shock. Clin Exp Immunol (2002) 128:59-66. doi: 10.1046/j.1365-2249.2002.01630.x

156. Jiang D, Scharffetter-Kochanek K. Mesenchymal Stem Cells Adaptively Respond to Environmental Cues Thereby Improving Granulation Tissue Formation and Wound Healing. Front Cell Dev Biol (2020) 8:697. doi: 10.3389/fcell.2020.00697

157. Ko JH, Kim HJ, Jeong HJ, Lee HJ, Oh JY. Mesenchymal Stem and Stromal Cells Harness Macrophage-Derived Amphiregulin to Maintain Tissue Homeostasis. Cell Rep (2020) 30:3806-20.e6. doi: 10.1016/j.celrep.2020. 02.062

158. Jiang D, Qi Y, Walker NG, Sindrilaru A, Hainzl A, Wlaschek M, et al. The Effect of Adipose Tissue Derived MSCs Delivered by a Chemically Defined Carrier on Full-Thickness Cutaneous Wound Healing. Biomaterials (2013) 34:2501-15. doi: 10.1016/j.biomaterials.2012.12.014

159. Akita S, Akino K, Hirano A, Ohtsuru A, Yamashita S. Noncultured Autologous Adipose-Derived Stem Cells Therapy for Chronic Radiation Injury. Stem Cells Int (2010) 2010:532704. doi: 10.4061/2010/532704

160. Javazon EH, Keswani SG, Badillo AT, Crombleholme TM, Zoltick PW, Radu AP, et al. Enhanced Epithelial Gap Closure and Increased Angiogenesis in Wounds of Diabetic Mice Treated With Adult Murine Bone Marrow Stromal Progenitor Cells. Wound Repair Regener (2007) 15:350-9. doi: 10.1111/ j.1524-475X.2007.00237.x

161. Nuschke A. Activity of Mesenchymal Stem Cells in Therapies for Chronic Skin Wound Healing. Organogenesis (2014) 10:29-37. doi: 10.4161/ org. 27405

162. Kim J, Hematti P. Mesenchymal Stem Cell-Educated Macrophages: A Novel Type of Alternatively Activated Macrophages. Exp Hematol (2009) 37:144553. doi: 10.1016/j.exphem.2009.09.004

163. Chen L, Tredget EE, Wu PY, Wu Y. Paracrine Factors of Mesenchymal Stem Cells Recruit Macrophages and Endothelial Lineage Cells and Enhance Wound Healing. PloS One (2008) 3:e1886. doi: 10.1371/journal. pone.0001886

164. Jiang D, Muschhammer J, Qi Y, Kugler A, de Vries JC, Saffarzadeh M, et al. Suppression of Neutrophil-Mediated Tissue Damage-A Novel Skill of Mesenchymal Stem Cells. Stem Cells (2016) 34:2393-406. doi: 10.1002/ stem.2417

165. Jiang D, de Vries JC, Muschhammer J, Sindrilaru A, Scharffetter-Kochanek K. Mouse Model of Immune Complex-Mediated Vasculitis in Dorsal Skin and Assessment of the Neutrophil-Mediated Tissue Damage. Bio Protoc (2017) 7:e2660. doi: 10.21769/BioProtoc.2660

166. Jiang D, Saffarzadeh M, Scharffetter-Kochanek K. In Vitro Demonstration and Quantification of Neutrophil Extracellular Trap Formation. Bio Protoc (2017) 7:e2386. doi: 10.21769/BioProtoc.2386

167. Zhang S, Chen L, Zhang G, Zhang B. Umbilical Cord-Matrix Stem Cells Induce the Functional Restoration of Vascular Endothelial Cells and Enhance Skin Wound Healing in Diabetic Mice Via the Polarized Macrophages. Stem Cell Res Ther (2020) 11:39. doi: 10.1186/s13287-0201561-x

168. Fong CY, Tam K, Cheyyatraivendran S, Gan SU, Gauthaman K, Armugam A, et al. Human Wharton's Jelly Stem Cells and its Conditioned Medium Enhance Healing of Excisional and Diabetic Wounds. J Cell Biochem (2014) 115:290-302. doi: 10.1002/jcb.24661

169. Barminko JA, Nativ NI, Schloss R, Yarmush ML. Fractional Factorial Design to Investigate Stromal Cell Regulation of Macrophage Plasticity. Biotechnol Bioeng (2014) 111:2239-51. doi: 10.1002/bit.25282

170. Ahangar P, Mills SJ, Cowin AJ. Mesenchymal Stem Cell Secretome as an Emerging Cell-Free Alternative for Improving Wound Repair. Int J Mol Sci (2020) 21:7038. doi: 10.3390/ijms21197038

171. Zhang QZ, Su WR, Shi SH, Wilder-Smith P, Xiang AP, Wong A, et al. Human Gingiva-Derived Mesenchymal Stem Cells Elicit Polarization of M2 Macrophages and Enhance Cutaneous Wound Healing. Stem Cells (2010) 28:1856-68. doi: 10.1002/stem.503

172. Uchiyama A, Motegi SI, Sekiguchi A, Fujiwara C, Perera B, Ogino S, et al. Mesenchymal Stem Cells-Derived MFG-E8 Accelerates Diabetic Cutaneous Wound Healing. J Dermatol Sci (2017) 86:187-97. doi: 10.1016/ j.jdermsci.2017.02.285

173. Nemeth K, Leelahavanichkul A, Yuen PS, Mayer B, Parmelee A, Doi K, et al. Bone Marrow Stromal Cells Attenuate Sepsis Via Prostaglandin E(2)- 
Dependent Reprogramming of Host Macrophages to Increase Their Interleukin-10 Production. Nat Med (2009) 15:42-9. doi: 10.1038/nm.1905

174. Qi Y, Jiang D, Sindrilaru A, Stegemann A, Schatz S, Treiber N, et al. TSG-6 Released From Intradermally Injected Mesenchymal Stem Cells Accelerates Wound Healing and Reduces Tissue Fibrosis in Murine Full-Thickness Skin Wounds. J Invest Dermatol (2014) 134:526-37. doi: 10.1038/jid.2013.328

175. Hu MS, Borrelli MR, Lorenz HP, Longaker MT, Wan DC. Mesenchymal Stromal Cells and Cutaneous Wound Healing: A Comprehensive Review of the Background, Role, and Therapeutic Potential. Stem Cells Int (2018) 2018:6901983. doi: 10.1155/2018/6901983

176. Basu A, Munir S, Mulaw MA, Singh K, Crisan D, Sindrilaru A, et al. A Novel S100a8/A9 Induced Fingerprint of Mesenchymal Stem Cells Associated With Enhanced Wound Healing. Sci Rep (2018) 8:6205. doi: 10.1038/s41598-01824425-9

177. Munir S, Basu A, Maity P, Krug L, Haas P, Jiang D, et al. TLR4-Dependent Shaping of the Wound Site by MSCs Accelerates Wound Healing. EMBO Rep (2020) 21:e48777. doi: 10.15252/embr.201948777

178. Wu RX, Ma C, Liang Y, Chen FM, Liu X. ECM-Mimicking Nanofibrous Matrix Coaxes Macrophages Toward an Anti-Inflammatory Phenotype: Cellular Behaviors and Transcriptome Analysis. Appl Mater Today (2020) 18:100508. doi: 10.1016/j.apmt.2019.100508

179. Smith TD, Nagalla RR, Chen EY, Liu WF. Harnessing Macrophage Plasticity for Tissue Regeneration. Adv Drug Delivery Rev (2017) 114:193-205. doi: 10.1016/j.addr.2017.04.012

180. Spiller KL, Koh TJ. Macrophage-Based Therapeutic Strategies in Regenerative Medicine. Adv Drug Delivery Rev (2017) 122:74-83. doi: 10.1016/j.addr.2017.05.010

181. Mariani E, Lisignoli G, Borzi RM, Pulsatelli L. Biomaterials: Foreign Bodies or Tuners for the Immune Response? Int J Mol Sci (2019) 20:636. doi: $10.3390 /$ ijms 20030636

182. Dziki JL, Huleihel L, Scarritt ME, Badylak SF. Extracellular Matrix Bioscaffolds as Immunomodulatory Biomaterials. Tissue Eng Part A (2017) 23:1152-9. doi: 10.1089/ten.tea.2016.0538

183. Bondioli E, Fini M, Veronesi F, Giavaresi G, Tschon M, Cenacchi G, et al. Development and Evaluation of a Decellularized Membrane From Human Dermis. J Tissue Eng Regener Med (2014) 8:325-36. doi: 10.1002/term.1530

184. He C, Yang Z, Jin Y, Qi X, Chu J, Deng X. Adm Scaffolds Generate a Proregenerative Microenvironment During Full-Thickness Cutaneous Wound Healing Through M2 Macrophage Polarization Via Lamtor1. Front Physiol (2018) 9:657. doi: 10.3389/fphys.2018.00657

185. Kajahn J, Franz S, Rueckert E, Forstreuter I, Hintze V, Moeller S, et al. Artificial Extracellular Matrices Composed of Collagen I and High Sulfated Hyaluronan Modulate Monocyte to Macrophage Differentiation Under Conditions of Sterile Inflammation. Biomatter (2012) 2:226-36. doi: 10.4161/biom.22855

186. Grotenhuis N, Vd Toom HF, Kops N, Bayon Y, Deerenberg EB, Mulder IM, et al. In Vitro Model to Study the Biomaterial-Dependent Reaction of Macrophages in an Inflammatory Environment. Br J Surg (2014) 101:98392. doi: $10.1002 / b j s .9523$

187. Rayahin JE, Buhrman JS, Zhang Y, Koh TJ, Gemeinhart RA. High and Low Molecular Weight Hyaluronic Acid Differentially Influence Macrophage Activation. ACS Biomater Sci Eng (2015) 1:481-93. doi: 10.1021/ acsbiomaterials.5b00181

188. Stern R, Maibach HI. Hyaluronan in Skin: Aspects of Aging and Its Pharmacologic Modulation. Clin Dermatol (2008) 26:106-22. doi: 10.1016/ j.clindermatol.2007.09.013

189. Vishwakarma A, Bhise NS, Evangelista MB, Rouwkema J, Dokmeci MR, Ghaemmaghami AM, et al. Engineering Immunomodulatory Biomaterials To Tune the Inflammatory Response. Trends Biotechnol (2016) 34:470-82. doi: 10.1016/j.tibtech.2016.03.009

190. Waters M, VandeVord P, Van Dyke M. Keratin Biomaterials Augment AntiInflammatory Macrophage Phenotype In Vitro. Acta Biomater (2018) 66:213-23. doi: 10.1016/j.actbio.2017.10.042

191. Poranki D, Whitener W, Howse S, Mesen T, Howse E, Burnell J, et al. Evaluation of Skin Regeneration After Burns In Vivo and Rescue of Cells After Thermal Stress In Vitro Following Treatment With a Keratin Biomaterial. J Biomater Appl (2014) 29:26-35. doi: 10.1177/0885328213513310
192. Pace LA, Plate JF, Smith TL, Van Dyke ME. The Effect of Human Hair Keratin Hydrogel on Early Cellular Response to Sciatic Nerve Injury in a Rat Model. Biomaterials (2013) 34:5907-14. doi: 10.1016/j.biomaterials.2013.04.024

193. Ashouri F, Beyranvand F, Beigi Boroujeni N, Tavafi M, Sheikhian A, Varzi AM, et al. Macrophage Polarization in Wound Healing: Role of Aloe Vera/ Chitosan Nanohydrogel. Drug Delivery Transl Res (2019) 9:1027-42. doi: 10.1007/s13346-019-00643-0

194. Mukherjee S, Darzi S, Paul K, Werkmeister JA, Gargett CE. Mesenchymal Stem Cell-Based Bioengineered Constructs: Foreign Body Response, Cross-Talk With Macrophages and Impact of Biomaterial Design Strategies for Pelvic Floor Disorders. Interface Focus (2019) 9:20180089. doi: 10.1098/rsfs.2018.0089

195. Yuan J, Hou Q, Zhong L, Dai X, Lu Q, Li M, et al. Sustained Release of Inhibitor From Bionic Scaffolds for Wound Healing and Functional Regeneration. Biomater Sci (2020) 8:5647-55. doi: 10.1039/D0BM00929F

196. Mashiko T, Takada H, Wu SH, Kanayama K, Feng J, Tashiro K, et al. Therapeutic Effects of a Recombinant Human Collagen Peptide Bioscaffold With Human Adipose-Derived Stem Cells on Impaired Wound Healing After Radiotherapy. J Tissue Eng Regener Med (2018) 12:1186-94. doi: $10.1002 /$ term. 2647

197. Geesala R, Bar N, Dhoke NR, Basak P, Das A. Porous Polymer Scaffold for On-Site Delivery of Stem Cells-Protects From Oxidative Stress and Potentiates Wound Tissue Repair. Biomaterials (2016) 77:1-13. doi: 10.1016/j.biomaterials.2015.11.003

198. Luu TU, Gott SC, Woo BW, Rao MP, Liu WF. Micro- and Nanopatterned Topographical Cues for Regulating Macrophage Cell Shape and Phenotype. ACS Appl Mater Interfaces (2015) 7:28665-72. doi: 10.1021/acsami.5b10589

199. Wu J, Chen A, Zhou Y, Zheng S, Yang Y, An Y, et al. Novel H2S-Releasing Hydrogel for Wound Repair Via in Situ Polarization of M2 Macrophages. Biomaterials (2019) 222:119398. doi: 10.1016/j.biomaterials.2019.119398

200. Xu HL, Chen PP, ZhuGe DL, Zhu QY, Jin BH, Shen BX, et al. Liposomes With Silk Fibroin Hydrogel Core to Stabilize bFGF and Promote the Wound Healing of Mice With Deep Second-Degree Scald. Adv Healthc Mater (2017) 6:1700344-69. doi: 10.1002/adhm.201700344

201. Rustad KC, Wong VW, Sorkin M, Glotzbach JP, Major MR, Rajadas J, et al. Enhancement of Mesenchymal Stem Cell Angiogenic Capacity and Stemness by a Biomimetic Hydrogel Scaffold. Biomaterials (2012) 33:80-90. doi: 10.1016/j.biomaterials.2011.09.041

202. Chantre CO, Campbell PH, Golecki HM, Buganza AT, Capulli AK, Deravi LF, et al. Production-Scale Fibronectin Nanofibers Promote Wound Closure and Tissue Repair in a Dermal Mouse Model. Biomaterials (2018) 166:96108. doi: 10.1016/j.biomaterials.2018.03.006

203. Xie J, Macewan MR, Ray WZ, Liu W, Siewe DY, Xia Y. Radially Aligned, Electrospun Nanofibers as Dural Substitutes for Wound Closure and Tissue Regeneration Applications. ACS Nano (2010) 4:5027-36. doi: 10.1021/nn101554u

204. Januszyk M, Gurtner GC. High-Throughput Single-Cell Analysis for Wound Healing Applications. Adv Wound Care (New Rochelle) (2013) 2:457-69. doi: 10.1089/wound.2012.0395

205. Bigaeva E, Uniken Venema WTC, Weersma RK, Festen EAM. Understanding Human Gut Diseases At Single-Cell Resolution. Hum Mol Genet (2020) 29:R51-R8. doi: 10.1093/hmg/ddaal30

206. Haensel D, Jin S, Sun P, Cinco R, Dragan M, Nguyen Q, et al. Defining Epidermal Basal Cell States During Skin Homeostasis and Wound Healing Using Single-Cell Transcriptomics. Cell Rep (2020) 30:3932-47. e6. doi: 10.1016/j.celrep.2020.02.091

207. Mahmoudi S, Mancini E, Xu L, Moore A, Jahanbani F, Hebestreit K, et al. Heterogeneity in Old Fibroblasts Is Linked to Variability in Reprogramming and Wound Healing. Nature (2019) 574:553-8. doi: 10.1038/s41586-019-1658-5

208. Guerrero-Juarez CF, Dedhia PH, Jin S, Ruiz-Vega R, Ma D, Liu Y, et al. Single-Cell Analysis Reveals Fibroblast Heterogeneity and Myeloid-Derived Adipocyte Progenitors in Murine Skin Wounds. Nat Commun (2019) 10:650. doi: $10.1038 / \mathrm{s} 41467-018-08247-\mathrm{x}$

209. Zhang Y, Wang D, Peng M, Tang L, Ouyang J, Xiong F, et al. Single-Cell RNA Sequencing in Cancer Research. J Exp Clin Cancer Res (2021) 40:1-17. doi: 10.1186/s13046-021-01874-1

210. Hicks SC, Townes FW, Teng M, Irizarry RA. Missing Data and Technical Variability in Single-Cell RNA-Sequencing Experiments. Biostatistics (2018) 19:562-78. doi: 10.1093/biostatistics/kxx053 
211. Kharchenko PV, Silberstein L, Scadden DT. Bayesian Approach to SingleCell Differential Expression Analysis. Nat Methods (2014) 11:740-2. doi: 10.1038/nmeth.2967

212. Yang KY, Ku M, Lui KO. Single-Cell Transcriptomics Uncover Distinct Innate and Adaptive Cell Subsets During Tissue Homeostasis and Regeneration. J Leukocyte Biol (2020) 108:1593-602. doi: 10.1002/ JLB.6MR0720-131R

213. Poblet E, Jimenez F, Escario-Travesedo E, Hardman J, HernándezHernández I, Agudo-Mena JL, et al. Eccrine Sweat Glands Associate With the Human Hair Follicle Within a Defined Compartment of Dermal White Adipose Tissue. Br J Dermatol (2018) 178:1163-72. doi: 10.1111/bjd.16436

214. Zhang Z, Shao M, Hepler C, Zi Z, Zhao S, An YA, et al. Dermal Adipose Tissue has High Plasticity and Undergoes Reversible Dedifferentiation in Mice. J Clin Invest (2019) 129:5327-42. doi: 10.1172/JCI130239

215. Nakamura-Ishizu A, Ito K, Suda T. Hematopoietic Stem Cell Metabolism During Development and Aging. Dev Cell (2020) 54:239-55. doi: 10.1016/ j.devcel.2020.06.029

216. Moura J, Madureira P, Leal E, Fonseca A, Carvalho E. Immune Aging in Diabetes and Its Implications in Wound Healing. Clin Immunol (2019) 200:43-54. doi: 10.1016/j.clim.2019.02.002
217. Sameri S, Samadi P, Dehghan R, Salem E, Fayazi N, Amini R. Stem Cell Aging in Lifespan and Disease: A State-of-the-Art Review. Curr Stem Cell Res Ther (2020) 15:362-78. doi: 10.2174/1574888X15666200213105155

218. Salminen A. Feed-Forward Regulation Between Cellular Senescence and Immunosuppression Promotes the Aging Process and Age-Related Diseases. Ageing Res Rev (2021) 67:101280. doi: 10.1016/j.arr.2021.101280

219. Schmieder A, Michel J, Schonhaar K, Goerdt S, Schledzewski K. Differentiation and Gene Expression Profile of Tumor-Associated Macrophages. Semin Cancer Biol (2012) 22:289-97. doi: 10.1016/j.semcancer.2012.02.002

Conflict of Interest: The authors declare that the research was conducted in the absence of any commercial or financial relationships that could be construed as a potential conflict of interest.

Copyright (c) $2021 \mathrm{Li}, \mathrm{Hou}$, Zhong, Zhao and Fu. This is an open-access article distributed under the terms of the Creative Commons Attribution License (CC BY). The use, distribution or reproduction in other forums is permitted, provided the original author(s) and the copyright owner(s) are credited and that the original publication in this journal is cited, in accordance with accepted academic practice. No use, distribution or reproduction is permitted which does not comply with these terms. 